\title{
State of the art on the physical mapping of the Y-chromosome in the Bovidae and comparison with other species - A review
}

\author{
Cristina Rossetti ${ }^{1, a}$, Viviana Genualdo ${ }^{1, a}$, Domenico Incarnato ${ }^{1}$, Filomena Mottola ${ }^{2}$, \\ Angela Perucatti ${ }^{1, *}$, and Alfredo Pauciullo ${ }^{3}$
}

\author{
* Corresponding Author: Angela Perucatti \\ Tel: +39-30-06499327718 \\ E-mail: angela.perucatti@cnr.it \\ ${ }^{1}$ Laboratory of Animal Cytogenetics and \\ Genomics, National Research Council (CNR), \\ ISPAAM, 80056 Portici (Napoli), Italy \\ 2 Department of Environmental, Biological and \\ Pharmaceutical Sciences and Technologies, \\ University of Campania "Luigi Vanvitelli", \\ 81100 Caserta, Italy \\ ${ }^{3}$ Department of Agricultural, Forest and \\ Food Sciences, University of Turin, 10095 \\ Grugliasco (TO), Italy \\ a Viviana Genualdo and Cristina Rossetti \\ contributed equally to this work. \\ ORCID \\ Cristina Rossetti \\ https://orcid.org/0000-0003-1944-0068 \\ Viviana Genualdo \\ https://orcid.org/0000-0001-7635-4508 \\ Domenico Incarnato \\ https://orcid.org/0000-0003-4945-986X \\ Filomena Mottola \\ https://orcid.org/0000-0001-9228-9398 \\ Angela Perucatti \\ https://orcid.org/0000-0003-4642-9921 \\ Alfredo Pauciullo \\ https://orcid.org/0000-0002-3140-9373
}

Submitted Oct 22, 2021; Revised Dec 10, 2021; Accepted Feb 1, 2022

\begin{abstract}
The next generation sequencing has significantly contributed to clarify the genome structure of many species of zootechnical interest. However, to date, some portions of the genome, especially those linked to a heterogametic nature such as the Y chromosome, are difficult to assemble and many gaps are still present. It is well known that the fluorescence in situ hybridization (FISH) is an excellent tool for identifying genes unequivocably mapped on chromosomes. Therefore, FISH can contribute to the localization of unplaced genome sequences, as well as to correct assembly errors generated by comparative bioinformatics. To this end, it is necessary to have starting points; therefore, in this study, we reviewed the physically mapped genes on the Y chromosome of cattle, buffalo, sheep, goats, pigs, horses and alpacas. A total of 208 loci were currently mapped by FISH. 89 were located in the malespecific region of the Y chromosome (MSY) and 119 were identified in the pseudoautosomal region (PAR). The loci reported in MSY and PAR were respectively: 18 and 25 in Bos taurus, 5 and 7 in Bubalus bubalis, 5 and 24 in Ovis aries, 5 and 19 in Capra hircus, 10 and 16 in Sus scrofa, 46 and 18 in Equus caballus. While in Vicugna pacos only 10 loci are reported in the PAR region. The correct knowledge and assembly of all genome sequences, including those of genes mapped on the Y chromosome, will help to elucidate their biological processes, as well as to discover and exploit potentially epistasis effects useful for selection breeding programs.
\end{abstract}

Keywords: Bovidae; Fluorescence In situ Hybridization; Genes; Y-chromosome

\section{INTRODUCTION}

In the last years, the genome of different farm animals, including pig [1], cow [2], buffalo [3], sheep [4], goat [5], horse [6], and camel [7], has been sequenced. Furthermore, there are species like the alpaca that have progressed slowly in the assembly because of their difficult karyotype $[8,9]$. The data obtained from these studies have significantly contributed to the understanding of domestication [10], to the selection of better breeds [11,12] and to the interaction between genetic traits and the environment $[13,14]$.

In the studies of mammalian genome and in particular of livestock species, the sex chromosomes (X and Y) have considerable importance. Especially the Y-chromosomes (Chr Y), which have undergone substantial evolutionary changes and losing about 95\% of the ancestral genesis [15]. The Chr Y is the smallest chromosome and consists of $2 \%$ to $3 \%$ of the haploid genome and, according to the species, may contain between 70 and 200 genes. It is involved in the segregation of the sex chromosomes in male meiosis. Therefore, it plays a key role for evolutionary studies, speciation, male infertility and/or subfertility due to its unique features, such as long non-recombining regions (NRYs), abundance of repetitive sequences, and holandric inheritance pattern [16]. This chromosome is generally 
separated into two distinct domains: the pseudoautosomal region (PAR) and the non-pseudoautosomal region, also known as the male-specific region of the $\mathrm{Y}$ chromosome (MSY). The PAR is a characteristic DNA region distinct from the autosomes that exhibits sequence homology between sex chromosomes [17].

The MSY region is not subject to pairing during meiosis. Therefore, it has been considered a NRY, although abundant recombination has been reported in humans $[18,19]$. Furthermore, the MSY contains gene families encoding multicopy proteins associated with male fertility $[15,20]$.

To date, Chr Y sequencing has been completed and characterized only in some species, including the human [18], the chimpanzee, the rhesus macaque [21], the mouse [22], the pig [23] and the horse [24]. Conversely, data are not available for other species. The molecular cytogenetic techniques, like the fluorescence in situ hybridization (FISH), offer a powerful tool in support of the bioinformatics pipelines following next generation sequencing projects. In fact, genomes assemblies are prone to errors, as they have been detected for instance in cattle, goats and sheep genomes by FISH $[25,26]$. Therefore, the use of the cytogenetic approaches are still fundamental for a correct assembly process. In fact, the FISH by bacterial artificial chromosome (BAC) clones allows assigning sequence contings to specific chromosomes and allows establishing the correct physical order of each DNA fragment, as demonstrated for both animal and vegetable sequencing processes $[27,28]$.

Since the knowledge of the genomes elevates to a different meaning if associated with chromosomes, both for the accuracy of the information and for the evaluation of all related biological aspects [29]; in the present study, we describe the current state of physical gene mapping by FISH in the main species of zootechnical interest (cattle, buffalo, sheep, goat, pig, horse, and alpaca). The choice to focus the attention on this point lies in the current gap of genome assembly data on $\mathrm{Chr} \mathrm{Y}$ and in the fundamental importance of cytogenetics in the study and interpretation of the genome [30,27,31], as already understood in 1920 by Hans Winkler when he coined the term "genome".

\section{BOVIDS Y-CHROMOSOME AND PSEUDOAUTOSOMAL REGION}

The Bovidae, in particular we considered Bos taurus (BTA), Bubalus bubalis (BBU), Ovis aries (OAR) and Capra hircus (CHI), play a role of fundamental importance for the livestock sector from an economic point of view. For this reason, these species have been investigated deeply from a genetic point of view, in particular for their fertility and consequently their sex chromosomes [32-35].

Although generally small, the Y-chromosome has differ- ent size and shape in the bovids. Indeed, in BTA the Chr Y is a small submetacentric, in BBU is a small acrocentric, while in both OAR and CHI is a very small metacentric [36,37]. However, in some breeds of bovids, the Chr Y is fused with an autosome, as in the case of the male of Gazella granti [38]. Moreover, the Chr Y shows few bands because it is almost completely heterochromatic. Besides, the pseudoautosomal boundary (PAB) separates the PAR with similar sequences between X and Y-chromosomes, from the MSY of reduced homology and specific to individual sex chromosomes [39]. In bovids, the genes present in the PAR of the Chr Y are the same in content and sequence as in the X chromosome [15].

\section{Bos taurus}

The bovine genome was among the first genomes to be partially sequenced, after the sequencing of the human one. The latest cattle genome assembly release (ARS-UCD1.2) of the whole genome, contains 29 pairs of the autosomes, the X chromosome, and unplaced sequences. Information on the $\mathrm{Chr} \mathrm{Y}$ is not available yet. Through the years, only few studies focused on the physical mapping of molecular markers by FISH [40-48]. These studies allowed confirming the presence and the precise location of eighteen genes on the MSY, as showed in Table 1 and Figure 1.

The PAR region is located at the telomere of the short arm of the $\mathrm{Chr} \mathrm{Y}$ and contains twenty five genes physically mapped $[34,49-51,45,39,52,53]$, as showed in Table 2 and Figure 2.

\section{Bubalus bubalis}

The buffalo genome has been recently sequenced with a contiguity surpassing both human and goat genomes [3]. The assembly UOA_WB_1 containis 24 pairs of the autosomes, the $\mathrm{X}$ chromosome and unplaced sequences. Also for the buffalo, no indications have been reported on Chr Y and, so far, only the studies by FISH allowed correctly placing five genes on the MSY (Table 1, Figure 1) [40,41,43-45, 47,48].

The buffalo PAR is located on the telomere of q-arm and contains seven genes already mapped (Table 2, Figure 2) [45, $39,52,53]$.

\section{Ovis aries/Capra hircus}

The assembly of OAR and CHI genomes are Oar_rambouillet_ v1.0. and Goat CVASU_BBG_1.0, respectively. The presence and precise location of five genes on the MSY were confirmed by FISH (Table 1, Figure 1) [40,41,43-45,47,48].

The PAR is located on the telomere of p-arm and it contains twenty four and nineteen genes physical mapped respectively for OAR and CHI (Table 2, Figure 2) [45,39,52,53].

\section{PIG Y-CHROMOSOME AND}


Table 1. Cytogenetic chromosome localisation of physically mapped MSY loci on the Y-chromosome of BTA, BBU, OAR, CHI, SSC, ECA, and VPA and their references

\begin{tabular}{|c|c|c|c|c|c|c|c|c|c|c|}
\hline \multicolumn{3}{|c|}{ Locus } & \multicolumn{7}{|c|}{ Physical localization } & \multirow{2}{*}{ References } \\
\hline Symbol & Name* & Protein type & BTA & BBU & OAR & $\mathrm{CHI}$ & SSC & ECA & VPA & \\
\hline AMELY & amelogenin, Y-linked & biomineral tissue development & - & - & - & - & Yp12-p13 & Yq14-q15 & - & $\begin{array}{l}\text { SSC: Quilter et al [54] } \\
\text { ECA: Raudsepp et al [60] }\end{array}$ \\
\hline $\begin{array}{l}\text { ANOSTY } \\
\text { ECA: KAL1 }\end{array}$ & anosmin 1 & peptidase inhibitor activity & - & - & - & - & - & Yq14-q15 & - & ECA: Janeka et al [24] \\
\hline ATP6VOCY & $\begin{array}{l}\text { ATPase, } \mathrm{H}+\text { transporting, } \\
\text { lysosomal } 16 \mathrm{kDa} \text {, V0 subu- } \\
\text { nit c }\end{array}$ & membrane transporter & - & - & - & - & - & Yq14-q15 & - & ECA: Paria et al [62] \\
\hline$B C 1.2$ & DNA segment & - & Yp13-p12 & - & - & - & - & - & - & BTA: Goldammer et al [43] \\
\hline BRY1 & $\begin{array}{l}\text { bovine male specific } \\
\text { repeat }\end{array}$ & - & Yp13 + Yp11-qter & - & - & - & - & - & - & BTA: Thomsen et al [41] \\
\hline BRY4.A & DNA segment & - & Yp11-q12 ter & - & - & - & - & - & - & BTA: Thomsen et al [41] \\
\hline$B Z Y .2$ & DNA segment & - & Yp11-q12 ter & - & - & - & - & - & - & BTA: Thomsen et al [41] \\
\hline CLY010 & DNA linear STS & - & - & - & - & - & - & Yq14 & - & ECA: Raudsepp et al [60] \\
\hline CLY018 & DNA linear STS & - & - & - & - & - & - & Yq14 & - & ECA: Raudsepp et al [60] \\
\hline CLY059 & DNA linear STS & - & - & - & - & - & - & Yq14 & - & ECA: Raudsepp et al [60] \\
\hline CLY074 & DNA linear STS & - & - & - & - & - & - & Yq14 & - & ECA: Raudsepp et al [60] \\
\hline CLYO77 & DNA linear STS & - & - & - & - & - & - & Yq14 & - & ECA: Raudsepp et al [60] \\
\hline $\begin{array}{l}\text { CUL } 4 B \\
\text { ECA: CULABY }\end{array}$ & $\begin{array}{l}\text { cullin 4B } \\
\text { ECA:Y-linked cullin 4B }\end{array}$ & $\begin{array}{l}\text { ubiquitin-protein transferase } \\
\text { activity }\end{array}$ & - & - & - & - & - & Yq14 & - & ECA: Paria et al [62] \\
\hline $\begin{array}{l}D D X 3 Y(D B Y) \\
\text { SSC: } D B Y \\
\text { ECA: } D D X 3 Y\end{array}$ & $\begin{array}{l}\text { DEAD-box helicase } 3 \\
\text { Y-linked }\end{array}$ & nucleic acid binding & - & - & - & - & Yp12-p13 & Yq14 & - & $\begin{array}{l}\text { SSC: Quilter et al [54] } \\
\text { ECA: Raudsepp et al [60] }\end{array}$ \\
\hline DYZ1 & DNA segment (DYZ-1) & - & Yp11-q11 & - & - & - & Yq12 & - & - & $\begin{array}{l}\text { BTA: Habermann et al [46] } \\
\text { SSC: Quilter et al [54] }\end{array}$ \\
\hline $\begin{array}{l}\text { DYZ10 } \\
\text { BTA-BBU-OAR-CHI: } \\
\text { IDVGA50 }\end{array}$ & Microsatellite & - & Yp12.1-q12.3 & Yq11-q1.10 & Yp11-q11 & Yp11-q11 & - & - & - & $\begin{array}{l}\text { BTA-BBU-OAR-CHI: Di Meo } \\
\text { et al [ } 45]\end{array}$ \\
\hline EIFTAY & $\begin{array}{l}\text { translation initiation factor } \\
1 \mathrm{AY}\end{array}$ & translation initiation factor activity & - & - & - & - & - & Yq14 & - & ECA: Paria et al [62] \\
\hline $\begin{array}{l}\text { EIF2S3 } \\
\text { SSC-ECA: EIF2s3Y }\end{array}$ & $\begin{array}{l}\text { eukaryotic translation } \\
\text { initiation factor } 2 \text { subunit } \\
\text { gamma }\end{array}$ & $\begin{array}{l}\text { translation factor activity, RNA } \\
\text { binding }\end{array}$ & - & - & - & - & Yp12-p13 & Yq14 & - & $\begin{array}{l}\text { SSC: Quilter et al [54] } \\
\text { ECA: Paria et al [62] }\end{array}$ \\
\hline EIF3CY & $\begin{array}{l}\text { eukaryotic translation } \\
\text { initiation factor, subunit C } \\
\text { on Y }\end{array}$ & $\begin{array}{l}\text { formation of cytoplasmic transla- } \\
\text { tion initiation complex }\end{array}$ & - & - & - & - & - & Yq14 & - & ECA: Paria et al [62] \\
\hline ETSTY1-5 & $\begin{array}{l}\text { equus testis-specific } \\
\text { transcript Y1-5 }\end{array}$ & - & - & - & - & - & - & Yq14 & - & ECA: Paria et al [62] \\
\hline ETSTY6 & $\begin{array}{l}\text { equus testis-specific } \\
\text { transcript } Y 6\end{array}$ & - & - & - & - & - & - & $\begin{array}{c}\text { Yq13 } \\
\text { (painting) }\end{array}$ & - & ECA: Paria et al [62] \\
\hline ETSTY7 & $\begin{array}{l}\text { equus testis-specific } \\
\text { transcript Y7 }\end{array}$ & - & - & - & - & - & - & $\begin{array}{c}\text { Yq13 } \\
\text { (painting) }\end{array}$ & - & ECA: Paria et al [62] \\
\hline$E T Y 1,4$ & Equus (transcript) Y1,4 & - & - & - & - & - & - & Yq14 & - & ECA: Paria et al [62] \\
\hline ETY2 & Equus (transcript) Y2 & - & - & - & - & - & - & Yq14 & - & ECA: Paria et al [62] \\
\hline ETY3 & Equus (transcript) Y3 & - & - & - & - & - & - & $\begin{array}{c}\text { Yq13 } \\
\text { (painting) }\end{array}$ & - & ECA: Paria et al [62] \\
\hline FBNY & DNA fragment & - & $\begin{array}{l}\text { Yq12-qter } \\
\text { (painting) }\end{array}$ & - & - & - & - & - & - & BTA: Weikard et al [44] \\
\hline HSFY1 & $\begin{array}{l}\text { heat shock transcription } \\
\text { factor Y-linked } 1\end{array}$ & transcriptional activators & $\begin{array}{l}\text { Yp11-q12ter } \\
\text { (painting) }\end{array}$ & - & - & - & - & - & - & BTA: Hamilton et al [48] \\
\hline HSFY2 & $\begin{array}{l}\text { heat shock transcription } \\
\text { factor Y-linked } 2\end{array}$ & transcriptional activators & $\begin{array}{l}\text { Yp11-q12ter } \\
\text { (painting) }\end{array}$ & - & - & - & - & & - & BTA: Hamilton et al [48] \\
\hline $\begin{array}{l}\text { KDM5D } \\
\text { ECA: JARID1D }\end{array}$ & lysine demethylase 5D & histone demethylase & - & - & - & - & - & Yq14 & - & ECA: Raudsepp et al [60] \\
\hline МАРЗК7/IPЗY & $\begin{array}{l}\text { mitogen-activated protein } \\
\text { kinase } 7 \text { interacting protein } \\
3 \text { on Y }\end{array}$ & protein kinase & - & - & - & - & - & Yq14 & - & ECA: Paria et al [62] \\
\hline MT-ND1Y & $\begin{array}{l}\text { miochondrially encoded } \\
\text { NADH dehydrogenase } 1 \text { on } \\
\text { Y }\end{array}$ & catalytic activity & - & - & - & - & - & Yq14 & - & ECA: Paria et al [62] \\
\hline NLGN4Y & neuroligin 4 Y-linked & $\begin{array}{l}\text { putative neuronal cell surface } \\
\text { protein involved in cell-cell-inter- } \\
\text { actions. }\end{array}$ & - & - & - & - & - & Yq14 & - & ECA: Paria et al [62] \\
\hline OY1.1 & protein coding & - & Yp13 + Yp11-qter & - & - & - & - & - & - & BTA: Thomsen et al [41] \\
\hline OY11.1 & protein coding & - & Yp11-q12 ter & - & - & - & - & - & - & BTA: Thomsen et al [41] \\
\hline RBMY & $\begin{array}{l}\text { RNA binding motif protein } \\
\text { Y-linked }\end{array}$ & binding protein & - & - & - & - & - & Yq14 & - & ECA: Paria et al [62] \\
\hline RFX5Y & regulatory factor $\mathrm{X} 5$ on $\mathrm{Y}$ & $\begin{array}{l}\text { DNA-binding transcription activa- } \\
\text { tor activity }\end{array}$ & - & - & - & - & - & Yq14 & - & ECA: Paria et al [62] \\
\hline RPS3AY & ribosomal protein S3A & ribosomal protein & - & - & - & - & - & Yq14 & - & ECA: Paria et al [62] \\
\hline
\end{tabular}

* The reported gene names follow the standards of the human gene nomenclature HGNC (Tweedie S, Braschi B, Gray KA, Jones TEM, Seal RL, Yates B, Bruford EA. Genenames. org: the HGNC and VGNC resources in 2021. Nucleic Acids Res. PMID: 33152070 PMCID: PMC7779007 D0I:10.1093/nar/gkaa980).

\section{PSEUDOAUTOSOMAL REGION}

The domestic pig, Sus scrofa (SSC), plays a key role in the meat industry, but it acquired great importance also as biomedical animal model for many human diseases. An updated version of its genome sequencing has been recently published as Sscrofa11.1. Despite the new version, the annotation is fully available for the autosomes and the $\mathrm{X}$ chromosome, while little data is available for the Chr Y. Thanks to the cytogenetic investigation by BAC clones and FISH [54-56], it was possible to obtain information about the Y morphology and the evolution of sex chromosome genes. The Chr Y is 
Table 1. Cytogenetic chromosome localisation of physically mapped MSY loci on the Y-chromosome of BTA, BBU, OAR, CHI, SSC, ECA, and VPA and their references (Continued)

\begin{tabular}{|c|c|c|c|c|c|c|c|c|c|c|}
\hline \multicolumn{3}{|c|}{ Locus } & \multicolumn{7}{|c|}{ Physical localization } & \multirow{2}{*}{ References } \\
\hline Symbol & Name* & Protein type & BTA & BBU & OAR & $\mathrm{CHI}$ & SSC & ECA & VPA & \\
\hline SH2-A-1 & DNA linear STS & - & - & - & - & - & - & Yq14 & - & ECA: Raudsepp et al [60] \\
\hline SH3-B-6 & DNA linear STS & - & - & - & - & - & - & Yq14 & - & ECA: Raudsepp et al [60] \\
\hline SH3-B-7 & DNA linear STS & - & - & - & - & - & - & Yq14 & - & ECA: Raudsepp et al [60] \\
\hline SRY & sex determining region $Y$ & transcriptional regulator & Yq12.3 & Yq17 & Yq12 & Yq12 & Yp12-p13 & Yq14 & - & $\begin{array}{l}\text { BTA/BBU/OAR/CHI: Di Meo } \\
\text { et al [45] } \\
\text { SSC: Yang et al [100] } \\
\text { ECA: Raudsepp et al [60] }\end{array}$ \\
\hline $\begin{array}{l}\text { STSP } 1 \\
\text { ECA: STS-Y }\end{array}$ & $\begin{array}{l}\text { steroid sulfatase (microso- } \\
\text { mal) pseudogene } 1\end{array}$ & $\begin{array}{l}\text { protein kinase, sulfuric ester } \\
\text { hydrolase activity }\end{array}$ & - & - & - & - & - & Yq14 & - & ECA: Paria et al [62] \\
\hline TBLTY & $\begin{array}{l}\text { transducin beta like } \\
\text { 1Y-linked }\end{array}$ & $\begin{array}{l}\text { transcription activation me- } \\
\text { diated by nuclear receptors }\end{array}$ & - & - & - & - & - & Yq14 & - & ECA: Paria et al [62] \\
\hline TMSB4Y & thymosin beta 4 Y-linked & actin monomer binding & - & - & - & - & - & Yq14 & - & ECA: Paria et al [62] \\
\hline $\begin{array}{l}\text { TSPY1 } \\
\text { BTA-OAR-CHI-SSC- } \\
\text { ECA: TSPY }\end{array}$ & $\begin{array}{l}\text { testis specific protein } \\
\text { Y-linked } 1\end{array}$ & $\begin{array}{l}\text { nucleosome assembly } \\
\text { protein }\end{array}$ & $\begin{array}{l}\text { Yp13-p11 } \\
\text { (painting) }\end{array}$ & & $\begin{array}{l}\text { Yp1.3-p1.2 } \\
\text { (painting) }\end{array}$ & $\begin{array}{l}\text { Yp1.3-p1.2 } \\
\text { (painting) }\end{array}$ & Yp11-p12 & Yq14 & - & $\begin{array}{l}\text { BTA/OAR/CHI: Hamilton } \\
\text { et al [47]; Vogel et al [42]; } \\
\text { Quilter et al [54] } \\
\text { ECA: Raudsepp et al [60] }\end{array}$ \\
\hline $\begin{array}{l}\text { TXLNGY } \\
\text { ECA: CYorf15 }\end{array}$ & $\begin{array}{l}\text { taxilin gamma pseudogene, } \\
\text { Y-linked }\end{array}$ & syntaxin binding & - & - & - & - & - & Yq14 & - & ECA: Paria et al [62] \\
\hline $\begin{array}{l}\text { UBA1 } \\
\text { SSC-ECA: UBETY }\end{array}$ & $\begin{array}{l}\text { ubiquitin-like modifier-acti- } \\
\text { vating enzyme } 1\end{array}$ & $\begin{array}{l}\text { ubiquitin activating enzyme } \\
\text { activity }\end{array}$ & - & - & - & - & Yp11-p12 & Yq14 & - & $\begin{array}{l}\text { SSC: Quilter et al [54] } \\
\text { ECA: Paria et al [62] }\end{array}$ \\
\hline UMN0301 & microsatellite & - & Yp12.1-q11 & - & - & - & - & - & - & BTA: Di Meo et al [45] \\
\hline UMN0304 & microsatellite & - & Yp12.1-q11 & Yq11-q1.10 & Yp11-q12 & Yp11-q12 & - & - & - & $\begin{array}{l}\text { BTA/BBU/OAR/CHI: Di Meo } \\
\text { et al [45] }\end{array}$ \\
\hline UMN0504 & microsatellite & - & Yp13-p12.2 & Yq21-q22 & - & - & - & - & - & BTA/BBU: Di Meo et al [45] \\
\hline USP9Y & $\begin{array}{l}\text { ubiquitin specific peptidase } \\
9 \text { Y-linked }\end{array}$ & $\begin{array}{l}\text { ubiquitin-protein or polyubiq- } \\
\text { uitin hydrolase }\end{array}$ & - & - & - & - & Yp12-p13 & Yq14 & - & $\begin{array}{l}\text { SSC: Quilter et al [54] } \\
\text { ECA: Raudsepp et al [60] }\end{array}$ \\
\hline UTY & $\begin{array}{l}\text { ubiquitously transcribed } \\
\text { tetratricopeptide repeat } \\
\text { containing, Y-linked }\end{array}$ & protein-protein interactions & - & - & - & - & Yp12-p13 & Yq14-q15 & - & $\begin{array}{l}\text { SSC: Quilter et al [54] } \\
\text { ECA: Raudsepp et al [60] }\end{array}$ \\
\hline Y2B17/YE1 & DNA linear STS & - & - & - & - & - & & Yq14 & - & ECA: Raudsepp et al [60] \\
\hline Y3B1 & DNA linear STS & - & - & - & - & - & - & Yq14 & - & ECA: Raudsepp et al [60] \\
\hline Y3B12 & DNA linear STS & - & - & - & - & - & - & Yq14 & - & ECA: Raudsepp et al [60] \\
\hline ҮзВ8 & DNA linear STS & - & - & - & - & - & - & Yq14 & - & ECA: Raudsepp et al [60] \\
\hline YIR2 & inverted repeat $2 Y$ & - & - & - & - & - & - & Yq14 & - & ECA: Paria et al [62] \\
\hline YM2 & DNA linear STS & - & - & - & - & - & - & Yq14 & - & ECA: Raudsepp et al [60] \\
\hline ZFY & zinc finger protein Y-linked & $\begin{array}{l}\text { DNA-binding transcription } \\
\text { factor activity }\end{array}$ & Yp12.2 & Yq110-q21 & Yp1.2 & Yp1.2 & Yp12-p13 & Yq14-q15 & - & $\begin{array}{l}\text { BTA/BBU/OAR/CHI: Di Meo } \\
\text { et al [45] } \\
\text { SSC: Quilter et al [54] } \\
\text { ECA: Raudsepp et al [60] }\end{array}$ \\
\hline ZNF33bY & zinc finger protein $33 \mathrm{~b}$ on $\mathrm{Y}$ & regulation of transcription & - & - & - & - & - & $\begin{array}{c}\text { Yq13 } \\
\text { (painting) }\end{array}$ & - & ECA: Paria et al [62] \\
\hline \multirow[t]{2}{*}{$\lambda E S 6.0$} & DNA segment & - & Yp12-p11 & - & - & - & - & - & - & BTA: Goldammer et al [43] \\
\hline & \multicolumn{2}{|c|}{ TOTAL LOCUS $=89$} & $\mathrm{BTAN}=18$ & $\mathrm{BBUN}=5$ & OAR $N=5$ & $\mathrm{CHIN}=5$ & $\operatorname{SSCN}=10$ & $\mathrm{ECAN}=46$ & $V P A N=0$ & \\
\hline
\end{tabular}

* The reported gene names follow the standards of the human gene nomenclature HGNC (Tweedie S, Braschi B, Gray KA, Jones TEM, Seal RL, Yates B, Bruford EA. Genenames. org: the HGNC and VGNC resources in 2021. Nucleic Acids Res. PMID: 33152070 PMCID: PMC7779007 D0I:10.1093/nar/gkaa980).

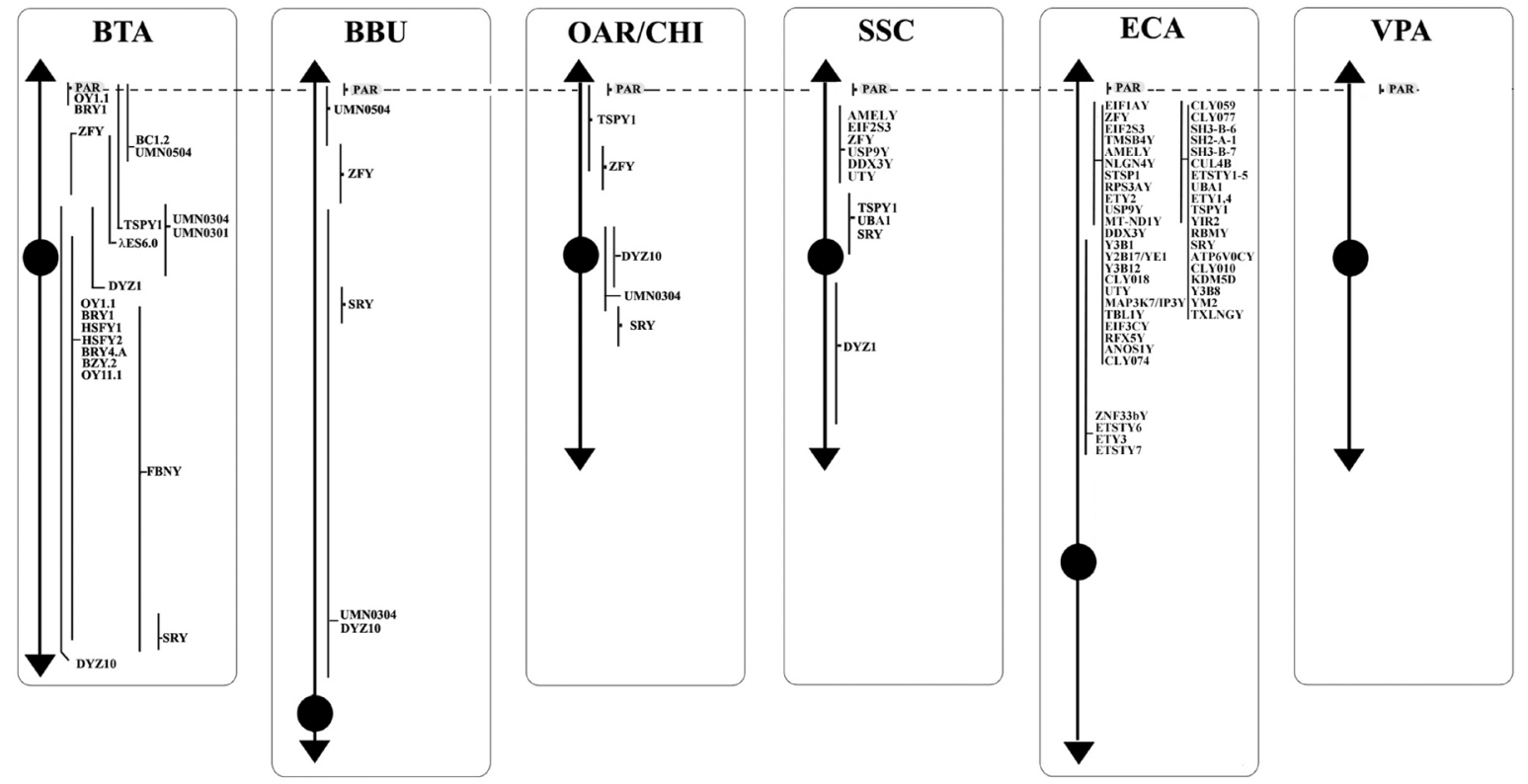

Figure 1. Schematic representation of MSY loci along the Y chromosomes of BTA, BBU, OAR, CHI, SSC, ECA, and VPA. MSY, male-specific region of the Y chromosome; BTA, Bos taurus; BBU, Bubalus bubalis; OAR, Ovis aries; CHI, Capra hircus; SSC, Sus scrofa; ECA, Equus caballus; VPA, Vicugna pacos. 
Table 2. Cytogenetic chromosome localisation of physically mapped PAR loci on the Y-chromosome of BTA, BBU, OAR, CHI, SSC, ECA and VPA, and their references

\begin{tabular}{|c|c|c|c|c|c|c|c|c|c|c|}
\hline \multicolumn{3}{|c|}{ Locus } & \multicolumn{7}{|c|}{ Physical localization } & \multirow{2}{*}{ References } \\
\hline Symbol & Name* & Protein type & BTA & BBU & OAR & $\mathrm{CHI}$ & SSC & ECA & VPA & \\
\hline $\begin{array}{l}\text { AKAP17A } \\
\text { ECA: SFRS17A }\end{array}$ & A-kinase anchoring protein $17 \mathrm{~A}$ & $\begin{array}{l}\text { A-kinase anchor protein } \\
17 \mathrm{~A}\end{array}$ & - & - & - & - & - & $\begin{array}{l}\text { Xp25tel/ } \\
\text { Yq15tel }\end{array}$ & - & ECA: Raudsepp and Chowdhary [63] \\
\hline $\begin{array}{l}\text { ANOS1 } \\
\text { BTA/OAR/CHI/SSC/ } \\
\text { VPA: KAL1 }\end{array}$ & anosmin 1 & $\begin{array}{l}\text { serine-type endopeptidase } \\
\text { inhibitor activity }\end{array}$ & $\begin{array}{c}\text { Xq43/ } \\
\text { Yp12.2-p13 }\end{array}$ & - & $\begin{array}{c}\text { Xp12/ } \\
\text { Yp12-p13 }\end{array}$ & $\begin{array}{c}\text { Xp12/ } \\
\text { Yp12-p13 }\end{array}$ & $\begin{array}{l}\text { Xp22.2/ } \\
\text { Yptel }\end{array}$ & - & $\begin{array}{l}\text { Xp16/ } \\
\text { Yq11 }\end{array}$ & $\begin{array}{l}\text { BTA/OAR/CHI: Das et al [39] } \\
\text { SSC: Das et al [55] } \\
\text { VPA: Avila et al [74] }\end{array}$ \\
\hline ARSD & arylsulfatase D & arylsulfatase $\mathrm{D}$ precursor & $\begin{array}{c}\text { Xq43/ } \\
\text { Yp12.2-p13 }\end{array}$ & - & $\begin{array}{c}\text { Xp12/ } \\
\text { Yp12-p13 }\end{array}$ & $\begin{array}{c}\text { Xp12/ } \\
\text { Yp12-p13 }\end{array}$ & - & $\begin{array}{l}\text { Xp25tel/ } \\
\text { Yq15tel }\end{array}$ & - & $\begin{array}{l}\text { BTA/OAR/CHI: Das et al [39] } \\
\text { ECA: Raudsepp and Chowdhary [63] }\end{array}$ \\
\hline $\begin{array}{l}\text { ARSL } \\
\text { BTA/OAR/CHI/ECA: } \\
\text { ARSE }\end{array}$ & arylsulfatase L & arylsulfatase $L$ precursor & $\begin{array}{c}\text { Xq43/ } \\
\text { Yp12.2-p13 }\end{array}$ & - & $\begin{array}{c}\text { Xp12/ } \\
\text { Yp12-p13 }\end{array}$ & $\begin{array}{l}\text { Xp12/ } \\
\text { Yp12-p13 }\end{array}$ & - & $\begin{array}{l}\text { Xp25tel/ } \\
\text { Yq15tel }\end{array}$ & - & $\begin{array}{l}\text { BTA/OAR/CHI: Das et al [39]; } \\
\text { ECA: Raudsepp and Chowdhary [63] }\end{array}$ \\
\hline ARSF & arylsulfatase $F$ & arylsulfatase $\mathrm{F}$ precursor & $\begin{array}{c}\text { Xq43/ } \\
\text { Yp12.2-p13 }\end{array}$ & - & $\begin{array}{c}X p 12 / \\
\text { Yp12-p13 }\end{array}$ & $\begin{array}{c}X p 12 / \\
\text { Yp12-p13 }\end{array}$ & $\begin{array}{l}\text { Xp24/ } \\
\text { Yp13 }\end{array}$ & $\begin{array}{l}\text { Xp25tel/ } \\
\text { Yq15tel }\end{array}$ & $\begin{array}{l}\text { Xp16/ } \\
\text { Yq11 }\end{array}$ & $\begin{array}{l}\text { BTA/OAR/CHI: Das et al [39]; } \\
\text { SSC: Das et al [55] } \\
\text { ECA: Raudsepp and Chowdhary [63] } \\
\text { VPA: Avila et al [74] }\end{array}$ \\
\hline ARSH & arylsulfatase family member $\mathrm{H}$ & arylsulfatase $\mathrm{H}$ precursor & $\begin{array}{c}\text { Xq43/ } \\
\text { Yp12.2-p13 }\end{array}$ & - & $\begin{array}{c}\text { Xp12/ } \\
\text { Yp12-p13 }\end{array}$ & $\begin{array}{c}\text { Xp12/ } \\
\text { Yp12-p13 }\end{array}$ & - & $\begin{array}{l}\text { Xp25tel/ } \\
\text { Yq15tel }\end{array}$ & - & $\begin{array}{l}\text { BTA/OAR/CHI: Das et al [39]; } \\
\text { ECA: Raudsepp and Chowdhary [63] }\end{array}$ \\
\hline ASMT & acetylserotonin 0-methyltransferase & methyltransferase activity & - & - & - & - & - & $\begin{array}{l}\text { Xp25tel/ } \\
\text { Yq15tel }\end{array}$ & - & ECA: Raudsepp and Chowdhary, [63] \\
\hline ASMTL & acetylserotonin 0-methyltransferase like & $\begin{array}{l}\text { O-methyltransferase activi- } \\
\text { ty }\end{array}$ & $\begin{array}{c}\text { Xq43/ } \\
\text { Yp12.2-p13 }\end{array}$ & $\begin{array}{c}\mathrm{Xq46/} \\
\text { Yq21-q22 }\end{array}$ & $\begin{array}{c}\text { Xp12/ } \\
\text { Yp12-p13 }\end{array}$ & $\begin{array}{c}\text { Xp12/ } \\
\text { Yp12-p13 }\end{array}$ & - & - & - & $\begin{array}{l}\text { BTA/OAR/CHI: Das et al [39] } \\
\text { BBU: Perucatti et al [52] }\end{array}$ \\
\hline CD99 & CD99 molecule (Xg blood group) & membrane glycoprotein & $\begin{array}{c}\text { Xq43/ } \\
\text { Yp12.2-p13 }\end{array}$ & - & $\begin{array}{c}\text { Xp12/ } \\
\text { Yp12-p13 }\end{array}$ & $\begin{array}{c}\text { Xp12/ } \\
\text { Yp12-p13 }\end{array}$ & - & $\begin{array}{l}\text { Xp25tel/ } \\
\text { Yq15tel }\end{array}$ & - & $\begin{array}{l}\text { BTA/OAR/CHI: Das et al [39] } \\
\text { ECA: Raudsepp and Chowdhary [63] }\end{array}$ \\
\hline CLCN4 & chloride voltage-gated channel 4 & membrane protein & - & & & & & & $\begin{array}{l}\text { Xp16/ } \\
\text { Yq11 }\end{array}$ & VPA: Avila et al [74] \\
\hline CRLF2 & cytokine receptor like factor 2 & membrane receptor & $\begin{array}{c}\text { Xq43/ } \\
\text { Yp12.2-p13 }\end{array}$ & - & $\begin{array}{c}\text { Xp12/ } \\
\text { Yp12-p13 }\end{array}$ & $\begin{array}{c}\text { Xp12/ } \\
\text { Yp12-p13 }\end{array}$ & $\begin{array}{l}\text { Xp24/ } \\
\text { Yp13 }\end{array}$ & $\begin{array}{l}\text { Xp25tel/ } \\
\text { Yq15tel }\end{array}$ & - & $\begin{array}{l}\text { BTA/OAR/CHI: Das et al [39] } \\
\text { SSC: Das et al [55] } \\
\text { ECA: Raudsepp and Chowdhary [63] }\end{array}$ \\
\hline CSF2RA & $\begin{array}{l}\text { colony stimulating factor } 2 \text { receptor } \\
\text { subunit alpha }\end{array}$ & membrane receptor & $\begin{array}{c}\text { Xq43/ } \\
\text { Yp12.2-p13 }\end{array}$ & - & $\begin{array}{c}X p 12 / \\
\text { Yp12-p13 }\end{array}$ & - & $\begin{array}{l}\text { Xp24/ } \\
\text { Yp13 }\end{array}$ & - & $\begin{array}{l}\text { Xp16/ } \\
\text { Yq11 }\end{array}$ & $\begin{array}{l}\text { BTA/OAR: Das et al [39]; Toder et al } \\
\text { [34] } \\
\text { SSC: Das et al [55]; } \\
\text { VPA: Avila et al [74] }\end{array}$ \\
\hline DHRSX & dehydrogenase/reductase X-linked & oxidoreductase activity & - & - & - & - & - & $\begin{array}{l}\text { Xp25tel/ } \\
\text { Yq15tel }\end{array}$ & - & ECA: Raudsepp and Chowdhary [63] \\
\hline DU171056 & BES & & $\begin{array}{c}\text { Xq43.1/ } \\
\text { Yp12.2-p13 }\end{array}$ & $\begin{array}{c}X \mathrm{q} 46 / \\
\text { Yq21-q22 }\end{array}$ & $\begin{array}{c}\text { Xp12/ } \\
\text { Yp12-p13 }\end{array}$ & & & & & BTA/BBU/OAR: Perucatti et al [52] \\
\hline $\begin{array}{l}\text { DXYS3 } \\
\text { (TGLA325) }\end{array}$ & DNA segment & - & $\begin{array}{l}X q 43.1 q 43.2 / \\
Y q 12.2-q 13\end{array}$ & $\begin{array}{l}\text { Xq46q47/ } \\
\text { Yq22 }\end{array}$ & $\begin{array}{c}\text { Xp12/ } \\
\text { Yp12-p13 }\end{array}$ & $\begin{array}{l}\text { Xp11-p14/ } \\
\text { Yp12-p13 }\end{array}$ & - & - & - & $\begin{array}{l}\text { BTA/BBU/OAR/CHI: lannuzzi et al } \\
\text { [51]; Di Meo et al [45] Piumi et al [50] }\end{array}$ \\
\hline $\begin{array}{l}\text { DXYS4 } \\
(\text { IOZARA1489) }\end{array}$ & DNA segment & - & $\begin{array}{l}\text { Xq43.1/ } \\
\text { Yp12.2 }\end{array}$ & Xq46-q47 & - & - & - & - & - & BTA/BBU: Prakash et al [49] \\
\hline EST BE750429 & DNA segment & - & $\begin{array}{l}\text { Xq43.1/ } \\
\text { Yp12.2 }\end{array}$ & $\begin{array}{l}X q 46-47 / \\
\text { Yq21-q22 }\end{array}$ & $\begin{array}{l}\text { Xp12/ } \\
\text { Yp12 }\end{array}$ & - & - & - & - & BTA/BBU/OAR: De Lorenzi et al [53] \\
\hline GPR143 & $\begin{array}{l}\text { G protein-coupled receptor } 143 \text { pseu- } \\
\text { dogene }\end{array}$ & $\begin{array}{l}\text { G protein-coupled receptor } \\
\text { activity }\end{array}$ & $\begin{array}{c}\text { Xq43/ } \\
\text { Yp12.2-p13 }\end{array}$ & - & $\begin{array}{c}X p 12 / \\
\text { Yp12-p13 }\end{array}$ & $\begin{array}{c}X p 12 / \\
\text { Yp12-p13 }\end{array}$ & $\begin{array}{l}\text { Xp24/ } \\
\text { Yp13 }\end{array}$ & - & $\begin{array}{l}\text { Xp16/ } \\
\text { Yq11 }\end{array}$ & $\begin{array}{l}\text { BTA/OAR/CHI: Das et al [39]; } \\
\text { SSC: Das et al [55] } \\
\text { VPA: Avila et al [74] }\end{array}$ \\
\hline GTPBP6 & GTP binding protein 6 (putative) & metal ion binding & - & - & - & - & - & $\begin{array}{l}\text { Xp25tel/ } \\
\text { Yq15tel }\end{array}$ & - & ECA: Raudsepp and Chowdhary [63] \\
\hline GYG2 & glycogenin 2 & glycosyltransferase activity & $\begin{array}{c}\text { Xq43/ } \\
\text { Yp12.2-p13 }\end{array}$ & - & $\begin{array}{c}\text { Xp12/ } \\
\text { Yp12-p13 }\end{array}$ & $\begin{array}{c}\text { Xp12/ } \\
\text { Yp12-p13 }\end{array}$ & - & $\begin{array}{l}\text { Xp25tel/ } \\
\text { Yq15tel }\end{array}$ & - & $\begin{array}{l}\text { BTA/OAR/CHI: Das et al [39]; } \\
\text { ECA: Raudsepp and Chowdhary [63] }\end{array}$ \\
\hline ILBRA & interleukin 3 receptor subunit alpha & cytokine receptor activity & $\begin{array}{c}\text { Xq43/ } \\
\text { Yp12.2-p13 }\end{array}$ & - & $\begin{array}{c}\text { Xp12/ } \\
\text { Yp12-p13 }\end{array}$ & $\begin{array}{c}\text { Xp12/ } \\
\text { Yp12-p13 }\end{array}$ & - & - & - & BTA/OAR/CHI: Das et al [39] \\
\hline MID1 & midline 1 & zinc ion binding & - & - & - & - & - & - & $\begin{array}{l}\text { Xp16/ } \\
\text { Yq11 }\end{array}$ & VPA: Avila et al [74] \\
\hline MXRA5 & matrix remodeling associated 5 & protein peptidase inhibitor & $\begin{array}{c}\text { Xq43/ } \\
\text { Yp12.2-p13 }\end{array}$ & - & $\begin{array}{l}\text { Xp12/ } \\
\text { Yp12-p13 }\end{array}$ & $\begin{array}{c}\text { Xp12/ } \\
\text { Yp12-p13 }\end{array}$ & $\begin{array}{l}\text { Xp24/ } \\
\text { Yp13 }\end{array}$ & $\begin{array}{l}\text { Xp25tel/ } \\
\text { Yq15tel }\end{array}$ & - & $\begin{array}{l}\text { BTA/OAR/CHI: Das et al [39]; } \\
\text { SSC: Das et al [55] } \\
\text { ECA: Raudsepp and Chowdhary [63] }\end{array}$ \\
\hline $\begin{array}{l}\text { NLGN4X } \\
\text { BTA/OAR/CHI: NLGN4 }\end{array}$ & neuroligin $4 \mathrm{X}$-linked & hydrolases & $\begin{array}{c}\text { Xq43/ } \\
\text { Yp12.2-p13 }\end{array}$ & - & $\begin{array}{c}\text { Xp12/ } \\
\text { Yp12-p13 }\end{array}$ & $\begin{array}{c}\text { Xp12/ } \\
\text { Yp12-p13 }\end{array}$ & - & - & - & BTA/OAR/CHI: Das et al [39] \\
\hline$O B P$ & $\begin{array}{l}\text { odorant binding protein (OBP porcine is } \\
\text { pool of isoforms) }\end{array}$ & phosphoprotein binding & - & - & - & - & $\begin{array}{l}\text { Xp24/ } \\
\text { Yp13 }\end{array}$ & - & - & SSC: Skinner et al [56] \\
\hline PLCXD1 & $\begin{array}{l}\text { phosphatidylinositol specific phospholi- } \\
\text { pase C X domain containing } 1\end{array}$ & $\begin{array}{l}\text { phosphoric diester hydro- } \\
\text { lase activity }\end{array}$ & - & - & - & - & - & $\begin{array}{l}\text { Xp25tel/ } \\
\text { Yq15tel }\end{array}$ & - & ECA: Raudsepp and Chowdhary [63] \\
\hline PNPLA4 & $\begin{array}{l}\text { patatin like phospholipase domain } \\
\text { containing } 4\end{array}$ & triglyceride lipase activity & $\begin{array}{c}\text { Xq43/ } \\
\text { Yp12.2-p13 }\end{array}$ & - & $\begin{array}{c}\text { Xp12/ } \\
\text { Yp12-p13 }\end{array}$ & $\begin{array}{c}\text { Xp12/ } \\
\text { Yp12-p13 }\end{array}$ & $\begin{array}{l}\text { Xp24/ } \\
\text { Yp13 }\end{array}$ & - & $\begin{array}{l}\text { Xp16/ } \\
\text { Yq11 }\end{array}$ & $\begin{array}{l}\text { BTA/OAR/CHI: Das et al [39] } \\
\text { SSC: Chen et al [91]; Das et al [55] } \\
\text { VPA: Avila et al [74] }\end{array}$ \\
\hline PPP2R3B & $\begin{array}{l}\text { protein phosphatase } 2 \text { regulatory subunit } \\
\text { B"beta }\end{array}$ & protein kinase binding & $\begin{array}{c}\text { Xq43/ } \\
\text { Yp12.2-p13 }\end{array}$ & - & $\begin{array}{c}\text { Xp12/ } \\
\text { Yp12-p13 }\end{array}$ & $\begin{array}{c}\text { Xp12/ } \\
\text { Yp12-p13 }\end{array}$ & - & $\begin{array}{l}\text { Xp25tel/ } \\
\text { Yq15tel }\end{array}$ & - & $\begin{array}{l}\text { BTA/OAR/CHI: Das et al [39]; } \\
\text { ECA: Raudsepp and Chowdhary [63] }\end{array}$ \\
\hline PRKXY & protein kinase X-linked & $\begin{array}{l}\text { CAMP-dependent protein } \\
\text { kinase activity }\end{array}$ & $\begin{array}{c}\text { Xq43/ } \\
\text { Yp12.2-p13 }\end{array}$ & - & $\begin{array}{c}\text { Xp12/ } \\
\text { Yp12-p13 }\end{array}$ & $\begin{array}{c}\text { Xp12/ } \\
\text { Yp12-p13 }\end{array}$ & $\begin{array}{l}\text { Xp24/ } \\
\text { Yp13 }\end{array}$ & $\begin{array}{l}\text { Xp25tel/ } \\
\text { Yq15tel }\end{array}$ & - & $\begin{array}{l}\text { BTA/OAR/CHI: Das et al [39]; } \\
\text { SSC: Das et al [55] } \\
\text { ECA: Raudsepp and Chowdhary [63] }\end{array}$ \\
\hline $\begin{array}{l}\text { PUDP } \\
\text { SSC: HDHD1 }\end{array}$ & pseudouridine 5'-phosphatase & phosphatase protein & - & & & & $\begin{array}{l}\text { Xp24/ } \\
\text { Yp13 }\end{array}$ & & & SSC: Das et al [55] \\
\hline SHOX & short stature homeobox & $\begin{array}{l}\text { DNA-binding transcription } \\
\text { factor activity }\end{array}$ & - & - & - & - & $\begin{array}{l}\text { Xp24/ } \\
\text { Yp13 }\end{array}$ & - & - & SSC: Skinner et al [56] \\
\hline SHROOM2 & shroom family member 2 & actin filament binding & - & - & - & - & $\begin{array}{l}\text { Xp24/ } \\
\text { Yp13 }\end{array}$ & - & $\begin{array}{l}\text { Xp16/ } \\
\text { Yq11 }\end{array}$ & $\begin{array}{l}\text { SSC: Das et al [55] } \\
\text { VPA: Avila et al [74] }\end{array}$ \\
\hline SLC25A6 & solute carrier family 25 member 6 & carrier protein ADP/ATP & $\begin{array}{l}\text { Xq42-q43.2/ } \\
\text { Yq12.2-q13 }\end{array}$ & $\begin{array}{l}\text { Xq46-47/ } \\
\text { Yq21-22 }\end{array}$ & $\begin{array}{c}\text { Xp12/ } \\
\text { Yp12-p13 }\end{array}$ & $\begin{array}{c}\text { Xp12/ } \\
\text { Yp12-p13 }\end{array}$ & $\begin{array}{l}\text { Xp24/ } \\
\text { Yp13 }\end{array}$ & $\begin{array}{l}\text { Xp25tel/ } \\
\text { Yq15tel }\end{array}$ & - & $\begin{array}{l}\text { BTA/BBU/OAR/CHI: Das et al [39]; } \\
\text { Di Meo et al [45] } \\
\text { SSC: Das et al [55] } \\
\text { ECA: Raudsepp and Chowdhary [63] }\end{array}$ \\
\hline
\end{tabular}

* The reported gene names follow the standards of the human gene nomenclature HGNC (Tweedie S, Braschi B, Gray KA, Jones TEM, Seal RL, Yates B, Bruford EA. Genenames. org: the HGNC and VGNC resources in 2021. Nucleic Acids Res. PMID: 33152070 PMCID: PMC7779007 D0I:10.1093/nar/gkaa980). 
Table 2. Cytogenetic chromosome localisation of physically mapped PAR loci on the Y-chromosome of BTA, BBU, OAR, CHI, SSC, ECA and VPA, and their references (Continued)

\begin{tabular}{|c|c|c|c|c|c|c|c|c|c|c|}
\hline \multicolumn{3}{|c|}{ Locus } & \multicolumn{7}{|c|}{ Physical localization } & \multirow{2}{*}{ References } \\
\hline Symbol & Name* & Protein type & BTA & BBU & OAR & $\mathrm{CHI}$ & SSC & ECA & VPA & \\
\hline STS & steroid sulfatase & $\begin{array}{l}\text { sulfuric ester hydrolase } \\
\text { activity }\end{array}$ & $\begin{array}{l}\text { Xq42-q43.2/ } \\
\text { Yq12.2-q13 }\end{array}$ & - & $\begin{array}{c}X p 12 / \\
\text { Yp12-p13 }\end{array}$ & - & $\begin{array}{l}\text { Xp24/ } \\
\text { Yp13 }\end{array}$ & - & $\begin{array}{l}\text { Xp16/ } \\
\text { Yq11 }\end{array}$ & $\begin{array}{l}\text { BTA: Das et al [39]; } \\
\text { OAR: Toder et al [34] } \\
\text { SSC: Das et al [55] } \\
\text { VPA: Avila et al [74] }\end{array}$ \\
\hline SW949 & microsatellite & - & - & - & - & - & $\begin{array}{l}\text { Xp24/ } \\
\text { Yp13 }\end{array}$ & - & $\cdot$ & SSC: Das et al [55] \\
\hline TBLTX & transducin beta like $1 \mathrm{X}$-linked & $\begin{array}{l}\text { transcription corepressor } \\
\text { activity }\end{array}$ & $\begin{array}{l}\text { Xq43.1/ } \\
\text { Yp12.2 }\end{array}$ & $\begin{array}{l}\text { Xq46-47/ } \\
\text { Yq21-q22 }\end{array}$ & $\begin{array}{l}\text { Xp12/ } \\
\text { Yp12 }\end{array}$ & - & $\begin{array}{l}\text { Xp24/ } \\
\text { Yp13 }\end{array}$ & - & - & $\begin{array}{l}\text { BTA/BBU/OAR: De Lorenzi et al [53] } \\
\text { SSC: Das et al [55] }\end{array}$ \\
\hline WWC3 & WWC family member 3 & kinase binding & $\cdot$ & & & & & & $\begin{array}{l}\text { Xp16/ } \\
\text { Yq11 }\end{array}$ & VPA: Avila et al [74] \\
\hline$X G$ & Xg glycoprotein (Xg blood group) & $\begin{array}{l}\text { glycoprotein plasma mem- } \\
\text { brane }\end{array}$ & - & - & - & - & - & $\begin{array}{l}\text { Xp25tel/ } \\
\text { Yq15tel }\end{array}$ & - & ECA: Raudsepp and Chowdhary [63] \\
\hline ZBED1 & zinc finger BED-type containing 1 & $\begin{array}{l}\text { DNA-binding transcription } \\
\text { protein }\end{array}$ & $\begin{array}{c}\text { Xq43/ } \\
\text { Yp12.2-p13 }\end{array}$ & - & $\begin{array}{c}\text { Xp12/ } \\
\text { Yp12-p13 }\end{array}$ & $\begin{array}{c}\text { Xp12/ } \\
\text { Yp12-p13 }\end{array}$ & - & $\begin{array}{l}\text { Xp25tel/ } \\
\text { Yq15tel }\end{array}$ & - & $\begin{array}{l}\text { BTA/OAR/CHI: Das et al [39]; } \\
\text { ECA: Raudsepp and Chowdhary [63] }\end{array}$ \\
\hline Total LOCUS & & & $\begin{array}{l}\text { BTA } \\
N=25\end{array}$ & $\begin{array}{l}\mathrm{BBU} \\
\mathrm{N}=7\end{array}$ & $\begin{array}{l}\text { OAR } \\
N=24\end{array}$ & $\begin{array}{l}\mathrm{CHI} \\
\mathrm{N}=19\end{array}$ & $\begin{array}{l}S S C \\
N=16\end{array}$ & $\begin{array}{c}E C A \\
N=18\end{array}$ & $\begin{array}{l}\text { VPA } \\
N=10\end{array}$ & \\
\hline
\end{tabular}

* The reported gene names follow the standards of the human gene nomenclature HGNC (Tweedie S, Braschi B, Gray KA, Jones TEM, Seal RL, Yates B, Bruford EA. Genenames. org: the HGNC and VGNC resources in 2021. Nucleic Acids Res. PMID: 33152070 PMCID: PMC7779007 D0l:10.1093/nar/gkaa980).

the smallest of the pig chromosomes, metacentric and constituted of about $50 \mathrm{Mb}$ in length as assessed by flow cytometry $[57,58]$. Chr Y short arm (Yp) is characterized by the presence of the most male-specific single-copy genes (physical mapped). Furthermore, given the highly repetitive nature of the long arm, to date, only a single copy sequence (DYZ1) is mapped on this chromosome portion (Table 1, Figure 1).

Regarding the information of the porcine PAR region, of sixteen loci only one is located in the terminal short arms of the sex chromosomes. Currently, the loci already known are only those cytogenetically mapped [55]. Moreover, the PAB lies next the shroom family member 2 (SHROOM2) or most proximal gene (Figure 2).
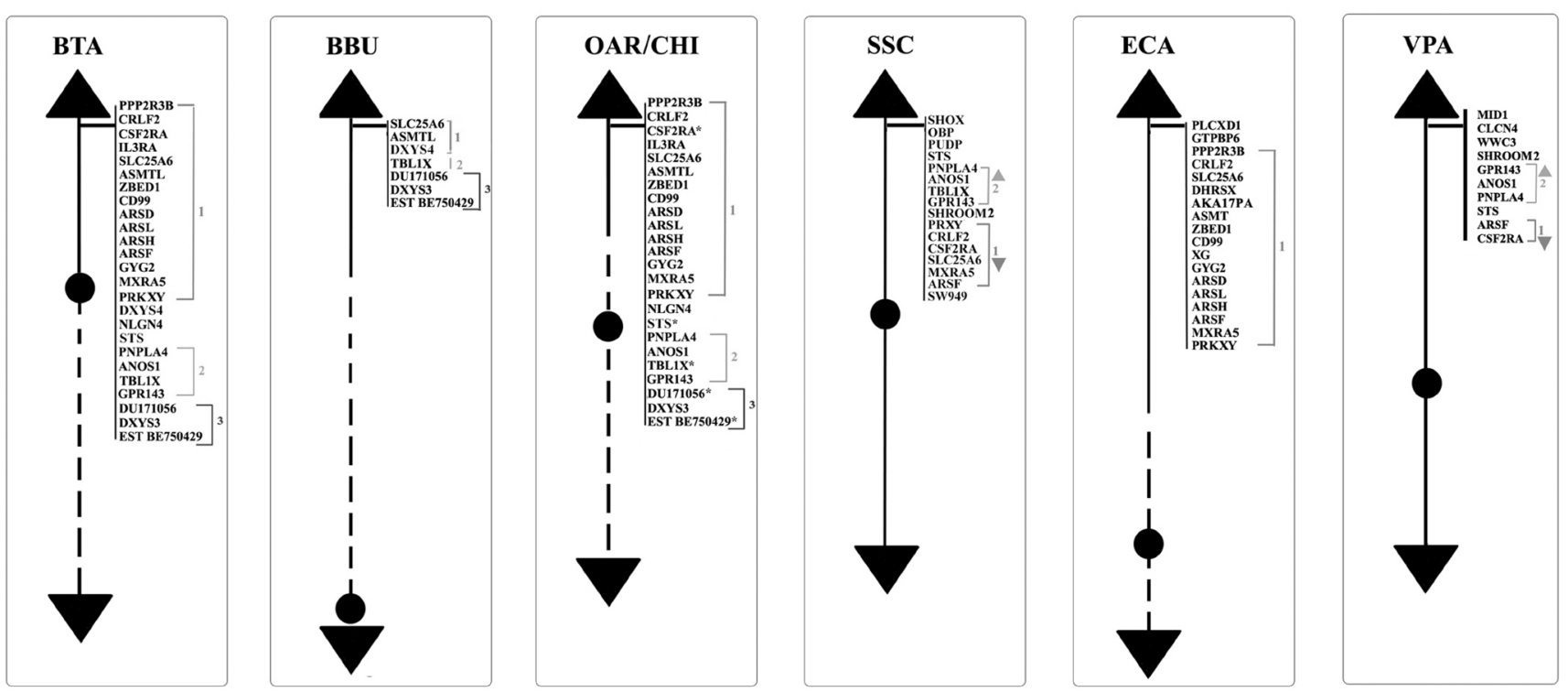

The horse, Equus caballus (ECA), is an economically and culturally important domestic species. The equine genome is approximately $2.68 \mathrm{~Gb}$ long and there are currently $\sim 1,150$ loci mapped by FISH with an average of one marker per $\sim 2.5$ $\mathrm{Mb}$ of the genome [59]. The ECA Y-chromosome is a small submetacentric, and forty-six genes have been mapped, as shown in Table 1 and Figure 1 [60-62,24]. The ECA genome is derived from a female, so the $\mathrm{Chr} Y$ has been poorly characterized.

Subsequently, through the sequencing of cDNA libraries, the gene content and the complete map of the euchromatic region were defined [24]. The map covers both the PAR and

Figure 2. Schematic representation of PAR loci along the $Y$ chromosomes of BTA, BBU, OAR, CHI, SSC, ECA, and VPA. PAR, pseudoautosomal region; BTA, Bos taurus; BBU, Bubalus bubalis; OAR, Ovis aries; CHI, Capra hircus; SSC, Sus scrofa; ECA, Equus caballus; VPA, Vicugna pacos. 
MSY regions [60,63]. A total of 129 markers, 110 sequencetagged site (STS) and 19 genes, were found in the PAR. This region includes the PAB, which is located between PRKXY and EIF1AY in the Y chromosome [64]. Studies conducted on ECA have shown the presence of duplicate genes both in MSY and PAR $[63,65]$. So far, this condition has been observed only in horses and, having no other information, further studies would be necessary to confirm or exclude these duplications also in other equids/perrisodactyls or mammals. To date, the current map contains approximately $\sim 400$ BAC clones [66]. In Paria's study of the 2009, through the use of the direct cDNA selection method, 29 genes and expressed sequence tag (ESTs) were identified and 23 out of them were known to be specific to the horse Y chromosome. To date, a total of 37 genes/transcripts from the horse MSY region were identified and showed that 20 genes are X-degenerate with known orthologs in other Eutherian species. The remaining 17 genes were acquired or novel and identified so far only in the horse or donkey Y chromosomes [62]. The PAR region is located at the telomere of the short $\mathrm{p}$ arm of the X chromosome and at the telomere of the long q-arm of the Y chromosome and contains 18 physical mapping genes (Table 2, Figure 2) [17].

\section{ALPACA Y-CHROMOSOME AND PSEUDOAUTOSOMAL REGION}

The alpaca, Vicugna pacos (VPA), is a species of Camelids originally from South America. The quality of its meat [67, 68], the opportunity to exploit it as a source of milk [69] and, especially, its fiber make this species of fundamental importance for the economy of many countries [70,71].

The reference genome for this species is the Vic.Pac 3.1, which has been annotated for about $90 \%$, and identifies $~ 76 \%$ of the genome to chromosomes [72,73]. The cytogenetic map currently known for the alpaca consists of 281 genes representative of all chromosomes [72]. So far, no genes have been identified by cytogenetic mapping on the Y-chromosome, except for ten loci on the PAR Yq-ter region (Table 2; Figure 2) because the CHORI-246 BAC library derives from a female alpaca [74]. The Alpaca Y-chromosome, according to the most recent physical mapping (Jevit et al [75]) is a small submetacentric, the smallest among of Old-World camels [76], and the PAR region is located in the long arm.

\section{DISCUSSION}

In this work, we report on the physical Y-gene mapping by FISH in the main farm animals species. Considering the existing gap in the genome assembly for the $\mathrm{Chr} \mathrm{Y}$, the present review is of great importance as one of the first indications to consider for a correct assembly. Moreover, the markers mapped on the Chr Y may offer useful indications for selection and have pratical implication in breeding programs for the biological function they may carry out. In fact, genes located on the $\mathrm{Y}$ chromosome are essential for spermatogenesis and male fertility, as demonstrated, for example, in Holstein bulls by association studies between Y-linked gene copy number variations (PRAMEY, HSFY, and ZNF) and fertility traits [77,78].

Although Y chromosome has never been a direct target for selection, fertility is always a significant factor in determining livestock productivity. In the majority of breeding programs for the farm animals, including those treated in the present study, the female-to-male sex ratio is significantly higher than one for the combination of the intensive artificial selection and the use of artificial insemination technology with high breeding value males. This condition greatly reduces the number of blood lineages and increases the consanguinity, as well as, the inbreeding depression on productive and reproductive traits, including fertility. Therefore, addressing this gap of knowledge will also increase the potential use of Y Chr markers for breeding purposes.

\section{Comparisons of genes mapped on Y-chromosome by FISH among farm animals}

To date, using the FISH method, it has been possible to map physically 208 loci belonging to the Y-chromosome of the species reviewed in the present study. In particular, 89 loci mapped in the non-pseudoautosomal region (Table 1) and 119 in the PAR region (Table 2). Regarding the comparison between PAR regions there is an interesting observation to do. This region is in the distal part of the Y-chromosome for all the species studied, but in BTA/OAR/CHI/SSC it is at the telomere of the $\mathrm{p}$-arm, while in ECA/BBU it was reported at the telomere of the q-arm (Figure 2). In addition, very recently, the same position has been confirmed also in VPA [75]. In particular, in this species, the Y-chromosome is very small and does not show distinct cytogenetic characteristic, so that it is difficult to identify the location of the centromere. Only with the use of the FISH technique by PAR BACs, it has been demonstrated that the alpaca Chr Y is submetacentric with a very small and short $\mathrm{p}$-arm and the PAR located at the telomere in the long q-arm [75].

Seventy-five out of 119 loci mapped in the PAR region and reviewed in this study were reported in bovids, whereas the other 44 were mapped in the other species. More in details, seven loci were mapped exclusively in the bovids (ASMTL, IL3RA, NLGN4, DU171056, DXYS3, DXYS4, EST BE750429) with the ASMTL and DXYS3 identified in all the four species (BTA, BBU, OAR, and CHI). DXYS4 physically located only in BTA and BBU, IL3RA and NLGN4X present in all except BBU, DU171056 and EST BE750429 absents in CHI. Three loci were mapped exclusively in VPA (CLCN4, MID1, WWC3), 
whereas four were identified only in SSC (OBP, PUDP, SW949, $S H O X)$. One locus, SHROOM2, was mapped in SSC and VPA, and six were exclusively identified in ECA (AKAP17A, ASMT, DHRSX, GTPBP6, PLCXD1, XG) (Table 2). PAR genes have maintained a high level of synteny and conservation between different species. Indeed, their comparison would lead to divide them into three sub-regions. The first consists of PPP2R3B, CRLF2, CSF2RA, IL3RA, SLC25A6, ASMTL, ZBED1, CD99, ARSD, ARSL, ARSH, ARSF, GYG2, MXRA5, PRKXY, DXYS4, and NLGN4 (sub-region 1), the second STS, PNPLA4, ANOS1, TBL1X and GPR143 (sub-region 2), the third presents only in bovids, with DU171056, DXYS3, EST BE750429.

Sub-region 1 is present in all the species we reviewed and the genes mapped in this area mostly maintained the same order. In fact, the sequences mapped by FISH in bovids and horses maintained synteny, with the exception of GYG2 in ECA, which is located between CD99 and ARSD and not between ARSF and MXRA5 as identified in bovids (Figure 2). Furthermore, in bovids, BTA and OAR-CHI showed the same genes mapped with the exception of CSF2RA present only in OAR, while in BBU, it is possible to find only three genes mapped out of the genes belonging to this subregion. In pig and alpaca, the order of this sub-region is reversed compared to other species, although only some of the sequences in this area have been mapped for both species (Figure 2). Furthermore, within the same sub-region 1 the order of $M X R A 5$ and $A R S F$ for pig, ARSF and CFS2RA for alpaca do not retain synteny compared to other species.

A similar matter is evident also for the sub-region 2, present in almost all the species of interest except for the ECA. In BTA and OAR-CHI the mapped sequences are the same. Among these, only TBL1X was not mapped to $\mathrm{CHI}$ and is, instead, the only gene present in BBU. For both pigs and alpacas this area appears in order before sub-region 1 (Figure 2). Furthermore, the STS gene in VPA mapped to the end of this area and not to the beginning as it can be found in BTA, OAR and SSC. Regarding the absence of this sub-region in the ECA, Janečka et al [24] reported a transposition of some PAR genes in the MSY region, such as TBL1Y, ANOS1Y, STSP1 (Figure 1). This transposition would facilitate the recombination between PAR and MSY. This situation would justify the deletions in the MSY region that can be found in horses with sexual development disorders [24].

About the genes of this subregion, TBL1X is implicated in the testosterone concentration, spermatogenesis, and sperm motility; it was used as marker and it resulted important for the predicition of reproductive performance [79].

The sub-region 3, as mentioned above, regards only bovids and it conserved in BTA, BBU, OAR, and CHI a perfect syn-

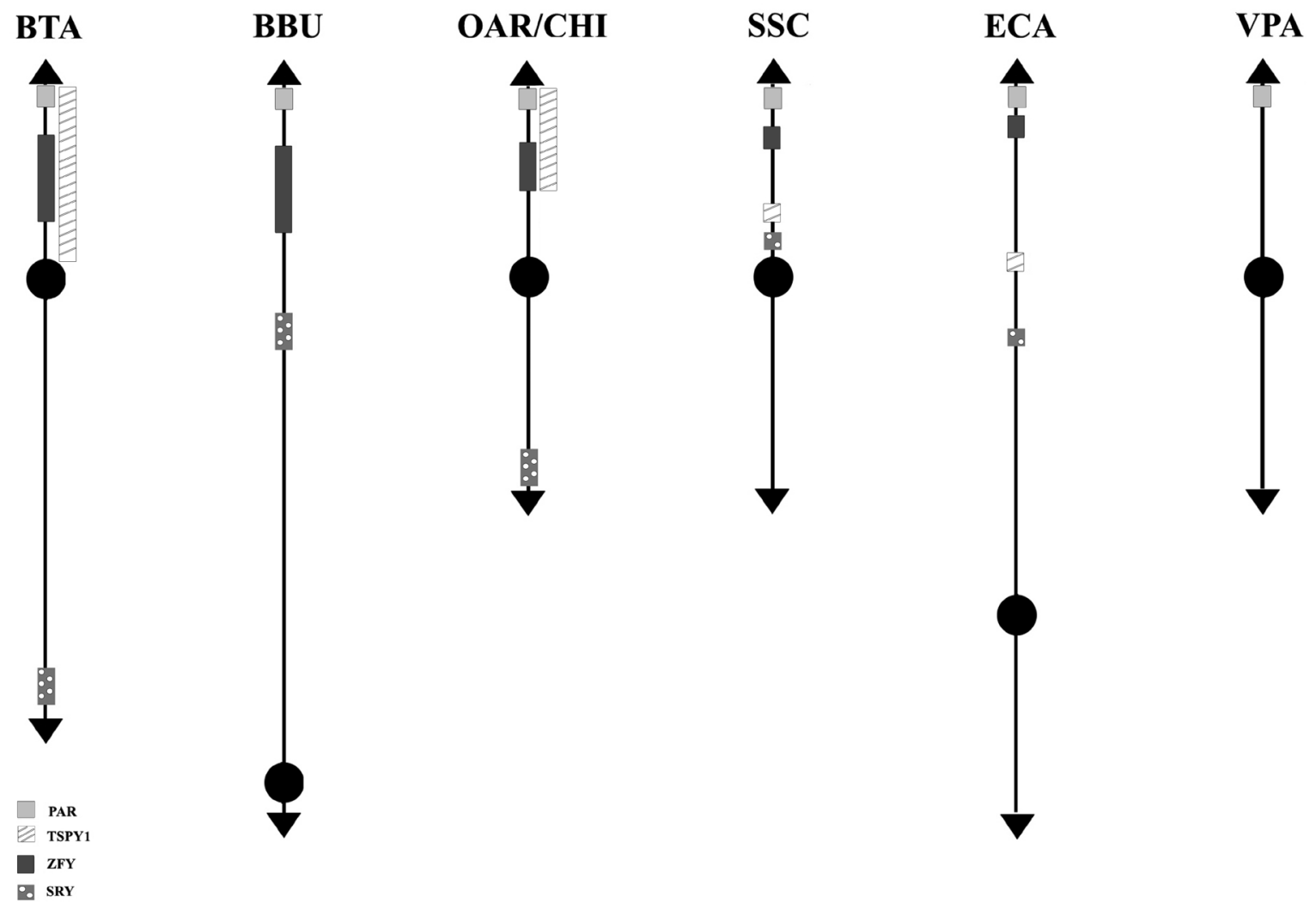

Figure 3. Schematic representation of SRY-ZFY-TSPY1 loci along the Y-chromosomes. No information has been found in VPA so far. VPA, Vicugna pacos. 
teny.

Concerning the 89 loci FISH mapped in the non pseudoautosomal region of the Chr Y (MSY), ECA represents the species reporting most of the loci currently mapped on $\mathrm{Chr}$ Y. Alone, it shows 46 positioned loci compared to BTA that has 18 mapped loci. About the other species, 10 loci were reported for SSC and 5 for BBU, OAR, and CHI. No genes were physically mapped to the alpaca Y-chromosome (Figure 1). Moreover, in this region, only the loci SRY, ZFY and TSPY1 were identified in most of the species investigated, that is BTA, OAR/CHI, SSC, and ECA; while BBU conserved only $S R Y$ and $Z F Y$ (Figure 3). The last two loci maintained a good synteny among the species, including in BBU where $Z F Y$ has been found in the telomeric region. In fact, according to $\mathrm{Di}$ Meo et al [45], the BBU Chr Y underwent a pericentric inversion compared to same chromosome in BTA. A similar situation has been described also for UMN0504 that is located near the PAR region only in these two species [45]. Regarding the locus TSPY1, it preserved synteny in the distal area of the short arm [48,42] in BTA, OAR and CHI. Conversely in SSC, this gene has been always reported near the centromeric region of the short arm [54]; and in ECA it has been reported in the euchromatic region of Y q-arm [60].

$S R Y, Z F Y$, and TSPY1 have been considered very important and used as markers for sexual screening as they are involved in spermatogenesis and sexual differentiation [80-82].

$D Y Z 1$, a male-specific repeat DNA sequence, has been mapped only in BTA and SSC Y [54]. In particular, concerning BTA, the gene maps in the Yp13-q12 region with a higher concentration in the centromeric region [40], as confirmed by Habermann et al [46].

The AMELY, EIF2S3, USP9Y, DDX3Y, UBA1, and UTY genes were mapped only in SSC and ECA.). In SSC, $A M E L Y$ is the first gene after the PAR region. However, according to Quilter et al [54], the orientation of the loci changes in ECA as a result of two rearrangements, so that the genes have the following order: EIF2S3, AMELY, USP9Y, DDX3Y, $U T Y$, and $U B A 1$ (Figure 1) [60,62]. Among them, AMELY is very important in the selection breeding programs because it represents a marker for the sex diagnosis of abnormalities involving the $\mathrm{Y}$ chromosome [83].

Instead EIF2S3, DDX3Y, UTY of this region together with SHROMM2 and SRY of MSY region were investigated for the level of their expression in the amniotic fluid [84]. This information can be very important in early sex determination by ensuring a targeted breeding program in species of economic interest.

UMN0304 and DYZ10 were mapped only in bovids. The former locus in BTA and OAR/CHI maps to the proximal pericentromeric regions of the $\mathrm{p}$ - and $\mathrm{q}$-arms, whereas in BBU covers almost the entire $Y$ chromosome except for the $\mathrm{R}$-positive telomeric band. The latter locus maps in BTA and
$\mathrm{BBU}$ as a painting, and in $\mathrm{OAR} / \mathrm{CHI}$ to the proximal pericentromeric region of the $\mathrm{p}$ - and $\mathrm{q}-\mathrm{arms}$ [45]. As regards DYZ10 and its different mapping, it must be considered that the data in literature are outdated in times former than the advent of new molecular technologies that allowed genomic libraries to be screened selectively. It would be interesting to localize again this gene, as well as many others, with new technologies like the PacBio sequencing [85] to be associated with classical methods such as FISH or Fiber-FISH. Concering the latter method, the Fiber-FISH is a technique that allows a significantly higher mapping resolution due to the direct visualization of chromatin fibers released from interphase nuclei that are extremely less condensed than the metaphase chromosomes observed by FISH. The Fiber-FISH is often used for determining size-gapping problems, locating delections, resolving chromatin breakpoints linked to diseases, estimating gene copy number variations, orientations, genes length, etc. [86,87].

Of the remaining genes, twelve were mapped only in cattle, and 37 in horses, as reported in Figure 1. The great interest in this species can be traced back to its ancient origins. The horse is in fact one of the first domesticated species that is integrated in the human working life as well as in his leisure activities [88]. Over the years, the interest in this species has increased because it is used in many rehabilitative activities or because it is used as a reference for the study of many pathologies, also considering the strong synteny between the chromosomes of this species with those of humans [89]. In addition, the fertility of stallions plays an essential role in the equine breeding industry (especially for racehorses), and although fertility is of primary importance for all species of zootechnical interest, this information is often limited also in this species.

From these results, the FISH technique turns out to be still a powerful tool contributing to the reduction of gaps currently present in sequencing processes.

The sequencing processes, in fact, in particular related to the Y-chromosome for livestock species, are still very complex and, in many respects, still little known due to the difficulty of assembling heterogametic genomes and the presence of highly repetitive ampliconic regions [15]. In addition, the sequencing of heterogametic genomes requires greater depth than in the homogametic genomes, resulting in an increase in costs [90]. One of the methods of sequencing sex chromosomes is based on the alignment of the heterogametic genome reads with the homogametic ones of the same species. In this way, those regions that are little reproduced on the homogametic chromosomes, are highlighted and are specific of the heterogametic chromosome [91].

As regards the PAR region, this Y-chromosome part is evolving [92,93], but, so far, only a few reports of PAR comparisons between species other than humans and mice have 
been undertaken $[65,39]$.

Implementing comparative studies on animal genomes by FISH physical mapping of markers along the chromosomes, it would allow a better understanding of the evolutionary process in the different species, including the discovery of complex rearrangements [45] and the filling up of the current gaps in animal genomes.

Furthermore, the knowledge of a correct Y-genes assembly along the chromosome will give the opportunity to investigate more intensively their epistasis effects [94] for instance in the regulation of autosomal gene expression or in the control of the individual fitness. In fact, as demonstrated in humans [95] and Drosophila [96] the Y-chromosome carries multiple genes that differentially affect the expression of hundreds of X-linked and autosomal genes with a functional impact on microtubule stability, metabolism and spermatogenesis [97]. Such epistatic genetic effect might be considered a consequence of the autosomal nature of both sex chromosomes [98], so that prior to becoming sex chromosomes have been involved in autosome-autosome interactions. Thus, although the $\mathrm{Y}$ chromosome is a specialized part of the genome, it can play a key role on autosomal gene expression and individual fitness by interacting with the rest of the genome [99].

\section{CONCLUSION}

In the recent years, the genome of many species has been completed, including farm animals of economic interest. However, portions, mostly concerning the Y chromosome, are still unknown or not correctly assembled. The difficulty lies in the absence of reference points that can validate sequence data generated by Next-Generation Sequencing (NGS). In this respect, a real contribution to reduce the gap of knowledge and possible assembly errors on Chr Y can come from the use of the FISH combined with its derived techniques like the Fiber-FISH. The Fiber-FISH would allow to walk on all chromosome starting from specific markers in order to cover any gap, establish the correct order of very near genes or identify the right location of old and new repeated sequences.

Furthermore, the physical map by FISH could be of support also in the study of the cytological characteristics of the chromatin that controls the gene expression and regulation when combined with immunoassay techniques.

The data reported in this mini-review may be a starting point for further studies and future applications in animal science.

\section{CONFLICT OF INTEREST}

We certify that there is no conflict of interest with any financial organization regarding the material discussed in the manu- script.

\section{FUNDING}

This study was funded by RIS Bufala, project number PAUA RIC_N_COMP_21_01.

\section{ACKNOWLEDGMENTS}

The authors wish to thank Mr. Raffaele Pappalardo (CNRISPAAM) for the technical support.

\section{REFERENCES}

1. Warr A, Affara N, Aken B, et al. An improved pig reference genome sequence to enable pig genetics and genomics research. GigaScience 2020;9:giaa051. https://doi.org/10.1093/giga science/giaa051

2. Rosen BD, Bickhart DM, Schnabel RD, et al. De novo assembly of the cattle reference genome with single-molecule sequencing. GigaScience 2020;9:giaa021. https://doi.org/10.1093/ gigascience/giaa021

3. Low WY, Tearle R, Bickhart DM, et al. Chromosome-level assembly of the water buffalo genome surpasses human and goat genomes in sequence contiguity. Nat Commun 2019;10: 260. https://doi.org/10.1038/s41467-018-08260-0

4. Archibald AL, Cockett NE, Dalrymple BP, et al. The sheep genome reference sequence: a work in progress. Anim Genet 2010;41:449-53. https://doi.org/10.1111/j.1365-2052.2010. 02100.x

5. Bickhart DM, Rosen BD, Koren S, et al. Single-molecule sequencing and chromatin conformation capture enable de novo reference assembly of the domestic goat genome. Nat Genet 2017;49:643-50. https://doi.org/10.1038/ng.3802

6. Chowdhary BP, Raudsepp T. The horse genome. In: Volff JN, editor. Vertebrate Genomes. Genome Dynamics Basel, Switzerland: Karger; 2006. Vol 2 pp. 97-110. https://doi.org/ 10.1159/000095098

7. Fitak RR, Mohandesan E, Corander J, Burger PA. The de novo genome assembly and annotation of a female domestic dromedary of North African origin. Mol Ecol Resour 2016; 16:314-24. https://doi.org/10.1111/1755-0998.12443

8. Bianchi NO, Larramendy ML, Bianchi MS, Cortés L. Karyological conservatism in South American camelids. Experientia 1986;42:622-4. https://doi.org/10.1007/BF01955563

9. Di Berardino D, Nicodemo D, Coppola G, et al. Cytogenetic characterization of alpaca (Lama pacos, fam. Camelidae) prometaphase chromosomes. Cytogenet Genome Res 2006; 115:138-44. https://doi.org/10.1159/000095234

10. Frantz LAF, Bradley DG, Larson G, Orlando L. Animal domestication in the era of ancient genomics. Nat Rev Genet 2020;21:449-60. https://doi.org/10.1038/s41576-020-0225-0 
11. Fonseca PAS, Suárez-Vega A, Marras G, Cánovas Á. GALLO: An $\mathrm{R}$ package for genomic annotation and integration of multiple data sources in livestock for positional candidate loci. Gigascience 2020;9:giaa149. https://doi.org/10.1093/ gigascience/giaal 49

12. Eusebi PG, Martinez A, Cortes O. Genomic tools for effective conservation of livestock breed diversity. Diversity 2020;12:8. https://doi.org/10.3390/d12010008

13. Bai Y, Sartor M, Cavalcoli J. Current status and future perspectives for sequencing livestock genomes. J Anim Sci Biotechnol 2012;3:8. https://doi.org/10.1186/2049-1891-3-8

14. Sánchez-Molano E, Kapsona VV, Ilska JJ, et al. Genetic analysis of novel phenotypes for farm animal resilience to weather variability. BMC Genet 2019;20:84. https://doi.org/10.1186/ s12863-019-0787-z

15. Liu R, Low WY, Tearle R, et al. New insights into mammalian sex chromosome structure and evolution using highquality sequences from bovine $\mathrm{X}$ and $\mathrm{Y}$ chromosomes. BMC Genomics 2019;20:1000. https://doi.org/10.1186/s12864019-6364-z

16. Dhanoa JK, Mukhopadhyay CS, Arora JS. Y-chromosomal genes affecting male fertility: a review. Vet World 2016;9: 783-91. https://doi.org/10.14202/vetworld.2016.783-791

17. Raudsepp T, Chowdhary BP. The eutherian pseudoautosomal region. Cytogenet Genome Res 2015;147:81-94. https://doi. org/10.1159/000443157

18. Skaletsky H, Kuroda-Kawaguchi T, Minx PJ, et al. The malespecific region of the human $\mathrm{Y}$ chromosome is a mosaic of discrete sequence classes. Nature 2003;423:825-37. https:// doi.org/10.1038/nature01722

19. Rozen S, Skaletsky H, Marszalek JD, et al. Abundant gene conversion between arms of palindromes in human and ape Y chromosomes. Nature 2003;423:873-6. https://doi. org/10.1038/nature 01723

20. Trombetta B, D’Atanasio E, Cruciani F. Patterns of interchromosomal gene conversion on the male-specific region of the human Y Chromosome. Front Genet 2017;8:54. https:// doi.org/10.3389/fgene.2017.00054

21. Hughes JF, Skaletsky H, Brown LG, et al. Strict evolutionary conservation followed rapid gene loss on human and rhesus Y chromosomes. Nature 2012;483:82-6. https://doi.org/10. 1038/nature10843

22. Soh YQ, Alföldi J, Pyntikova T, et al. Sequencing the mouse $\mathrm{Y}$ chromosome reveals convergent gene acquisition and amplification on both sex chromosomes. Cell 2014;159:80013. https://doi.org/10.1016/j.cell.2014.09.052

23. Skinner BM, Sargent CA, Churcher C, et al. The pig X and Y-chromosomes: structure, sequence, and evolution. Genome Res 2016;26:130-9. https://doi.org/10.1101/gr.188839.114

24. Janečka JE, Davis BW, Ghosh S, et al. Horse Y chromosome assembly displays unique evolutionary features and putative stallion fertility genes. Nat Commun 2018;9:2945. https://doi. org/10.1038/s41467-018-05290-6

25. De Lorenzi L, Parma P. Identification of some errors in the genome assembly of bovidae by FISH. Cytogenet Genome Res 2020;160:85-93. https://doi.org/10.1159/000506221

26. O'Connor RE, Fonseka G, Frodsham R, et al. Isolation of subtelomeric sequences of porcine chromosomes for translocation screening reveals errors in the pig genome assembly. Anim Genet 2017;48:395-403. Erratum in: Anim Genet 2017;48:628. https://doi.org/10.1111/age.12548

27. O'Connor C. Fluorescence in situ hybridization (FISH). Nature Education 2008;1:171.

28. Bubendorf L, Jürgen Grote H, Syrjänen K. CHAPTER 36 Molecular techniques. In: Bibbo M, Wilbur D, editors. Comprehensive cytopathology (Third Edition). W.B. Saunders; 2008. pp. 1071-90. https://doi.org/10.1016/B978-1416042082.10036-3

29. Deakin JE, Potter S, O'Neill R, et al. Chromosomics: bridging the gap between genomes and chromosomes. Genes (Basel) 2019;10:627. https://doi.org/10.3390/genes10080627

30. O'Connor SJM, Turner KR, Barrans SL. Practical application of fluorescent in situ hybridization techniques in clinical diagnostic laboratories. In: Nielsen BS, Jones J, editors. In situ hybridization protocols. Methods in molecular biology. New York, NY, USA: Humana; 2020. vol 2148. pp. 35-70. https://doi.org/10.1007/978-1-0716-0623-0_3

31. Levsky JM, Singer RH. Fluorescence in situ hybridization: past, present and future. J Cell Sci 2003;116(Pt 14):2833-8. https://doi.org/10.1242/jcs.00633

32. Rubes J, Musilova P, Kopecna O, Kubickova S, Cernohorska $\mathrm{H}$, Kulemsina AI. Comparative molecular cytogenetics in cetartiodactyla. Cytogenet Genome Res 2012;137:194-207. https://doi.org/10.1159/000338932

33. Graphodatsky AS, Trifonov VA, Stanyon R. The genome diversity and karyotype evolution of mammals. Mol Cytogenet 2011;4:22. https://doi.org/10.1186/1755-8166-4-22

34. Toder R, Gläser B, Schiebel K, et al. Genes located in and near the human pseudoautosomal region are located in the X-Y pairing region in dog and sheep. Chromosome Res 1997; 5:301-6. https://doi.org/10.1023/B:CHRO.0000038760.846 $05.0 \mathrm{~d}$

35. Yeh CC, Taylor JF, Gallagher DS, Sanders JO, Turner JW, Davis SK. Genetic and physical mapping of the bovine X chromosome. Genomics 1996;32:245-52. https://doi.org/10. 1006/geno.1996.0111

36. lannuzzi L. Standard karyotype of the river buffalo (Bubalus bubalis $\mathrm{L} ., 2 \mathrm{n}=50$ ). Report of the committee for the standardization of banded karyotypes of the river buffalo. Cytogenet Cell Genet 1994;67:102-13. https://doi.org/10.1159/00013 3808

37. Cribiu EP, Di Berardino D, Di Meo GP, et al. International system for chromosome nomenclature of domestic bovids (ISCNDB 2000). Cytogenet Cell Genet 2001;92:283-99. https:// 
doi.org/10.1159/000056917

38. Gallagher DS, Womack JE. Chromosome conservation in the bovidae. J Hered 1992;83:287-98. https://doi.org/10. 1093/oxfordjournals.jhered.a111215

39. Das PJ, Chowdhary BP, Raudsepp T. Characterization of the bovine pseudoautosomal region and comparison with sheep, goat, and other mammalian pseudoautosomal regions. Cytogenet Genome Res 2009;126:139-47. https://doi.org/10. $1159 / 000245913$

40. Perret J, Shia YC, Fries R, Vassart G, Georges M. A polymorphic satellite sequence maps to the pericentric region of the bovine Y chromosome. Genomics 1990;6:482-90. https:// doi.org/10.1016/0888-7543(90)90478-d

41. Thomsen PD, Jørgensen CB. Distribution of two conserved, male-enriched repeat families on the Bos taurus $\mathrm{Y}$ chromosome. Mamm Genome 1994;5:171-3. https://doi.org/10.1007/ BF00352350

42. Vogel T, Borgmann S, Dechend F, Hecht W, Schmidtke J. Conserved Y-chromosomal location of TSPY in Bovidae. Chromosome Res 1997;5:182-5. https://doi.org/10.1023/ A:1018494914182

43. Goldammer T, Brunner RM, Schwerin M. Comparative analysis of $\mathrm{Y}$ chromosome structure in Bos taurus and B. indicus by FISH using region-specific, microdissected, and locus-specific DNA probes. Cytogenet Cell Genet 1997;77: 238-41. https://doi.org/10.1159/000134584

44. Weikard R, Kühn C, Brunner RM, et al. Sex determination in cattle based on simultaneous amplification of a new malespecific DNA sequence and an autosomal locus using the same primers. Mol Reprod Dev 2001;60:13-9. https://doi. org/10.1002/mrd.1056

45. Di Meo GP, Perucatti A, Floriot S. et al. Chromosome evolution and improved cytogenetic maps of the $\mathrm{Y}$ chromosome in cattle, zebu, river buffalo, sheep and goat. Chromosome Res 2005;13:349-55. https://doi.org/10.1007/s10577-0052688-4

46. Habermann F, Winter A, Olsaker I, Reichert P, Fries R. Validation of sperm sexing in the cattle (Bos taurus) by dual colour fluorescence in situ hybridization. J Anim Breed Genet 2005;122(Suppl 1):22-7. https://doi.org/10.1111/j. 1439-0388.2005.00488.x

47. Hamilton CK, Favetta LA, Di Meo GP, et al. Copy number variation of testis-specific protein, Y-encoded (TSPY) in 14 different breeds of cattle (Bos taurus). Sex Dev 2009;3:20513. https://doi.org/10.1159/000228721

48. Hamilton CK, Revay T, Domander R, Favetta LA, King WA. A large expansion of the HSFY gene family in cattle shows dispersion across Yq and testis-specific expression. PLoS One 2011;6:e17790. https://doi.org/10.1371/journal.pone. 0017790

49. Prakash B, Olsaker I, Gustavsson I, Chowdhary BP. FISH mapping of three bovine cosmids to cattle, goat, sheep and buffalo X chromosomes. Hereditas 1997;126:115-9. https:// doi.org/10.1111/j.1601-5223.1997.00115.X

50. Piumi F, Schibler L, Vaiman D, Oustry A, Cribiu EP. Comparative cytogenetic mapping reveals chromosome rearrangements between the $\mathrm{X}$ chromosomes of two closely related mammalian species (cattle and goats). Cytogenet Cell Genet 1998;81:36-41. https://doi.org/10.1159/000015004

51. Iannuzzi L, Di Meo GP, Perucatti A, Incarnato D, Schibler L, Cribiu EP. Comparative FISH mapping of bovid X chromosomes reveals homologies and divergences between the subfamilies bovinae and caprinae. Cytogenet Cell Genet 2000;89:171-6. https://doi.org/10.1159/000015607

52. Perucatti A, Genualdo V, Iannuzzi A, et al. Advanced comparative cytogenetic analysis of $\mathrm{X}$ chromosomes in river buffalo, cattle, sheep, and human. Chromosome Res 2012; 20:413-25. https://doi.org/10.1007/s10577-012-9285-0

53. De Lorenzi L, Genualdo V, Perucatti A, Iannuzzi A, Iannuzzi L, Parma P. Physical mapping of 20 unmapped fragments of the btau_ 4.0 genome assembly in cattle, sheep and river buffalo. Cytogenet Genome Res 2013;140:29-35. https://doi.org/10. $1159 / 000350869$

54. Quilter CR, Blott SC, Mileham AJ, Affara NA, Sargent CA, Griffin DK. A mapping and evolutionary study of porcine sex chromosome genes. Mamm Genome 2002;13:588-94. https://doi.org/10.1007/s00335-002-3026-1

55. Das PJ, Mishra DK, Ghosh S, et al. Comparative organization and gene expression profiles of the porcine pseudoautosomal region. Cytogenet Genome Res 2013;141:26-36. https://doi. org $/ 10.1159 / 000351310$

56. Skinner BM, Lachani K, Sargent CA, Affara NA. Regions of $\mathrm{XY}$ homology in the pig $\mathrm{X}$ chromosome and the boundary of the pseudoautosomal region. BMC Genet 2013;14:3. https:// doi.org/10.1186/1471-2156-14-3

57. Cornefert-Jensen F, Hare WC, Abt DA. Identification of the sex chromosomes of the domestic pig. J Hered 1968;59:2515. https://doi.org/10.1093/oxfordjournals.jhered.a107710

58. Grunwald D, Geffrotin C, Chardon P, Frelat G, Vaiman M. Swine chromosomes: flow sorting and spot blot hybridization. Cytometry 1986;7:582-8. https://doi.org/10.1002/cyto.9900 70613

59. Chowdhary BP, Paria N, Raudsepp T. Potential applications of equine genomics in dissecting diseases and fertility. Anim Reprod Sci 2008;107:208-18. https://doi.org/10.1016/j.ani reprosci.2008.04.010

60. Raudsepp T, Santani A, Wallner B, et al. A detailed physical map of the horse Y chromosome. Proc Natl Acad Sci USA 2004;101:9321-6. https://doi.org/10.1073/pnas.0403011101

61. Paria N. Discovery of candidate genes for stallion fertility from the horse Y chromosome [Doctoral Dissertation]. College Station, TX, USA: Texas A\&M University; 2009.

62. Paria N, Raudsepp T, Pearks Wilkerson AJ, et al. A gene catalogue of the euchromatic male-specific region of the 
horse $\mathrm{Y}$ chromosome: comparison with human and other mammals. PLoS One 2011;6:e21374. https://doi.org/10. 1371/journal.pone.0021374

63. Raudsepp T, Chowdhary BP. The horse pseudoautosomal region (PAR):characterization and comparison with the human, chimp and mouse PARs. Cytogenet Genome Res 2008;121:102-9. https://doi.org/10.1159/000125835

64. Raudsepp T, Das PJ, Avila F, Chowdhary BP. The pseudoautosomal region and sex chromosome aneuploidies in domestic species. Sex Dev 2012;6:72-83. https://doi.org/10. $1159 / 000330627$

65. Raudsepp T, Gustafson-Seabury A, Durkin K, et al. A 4,103 marker integrated physical and comparative map of the horse genome. Cytogenet Genome Res 2008;122:28-36. https://doi. org/10.1159/000151313

66. Chowdhary BP, Raudsepp T. The horse genome derby: racing from map to whole genome sequence. Chromosome Res 2008;16:109-27. https://doi.org/10.1007/s10577-008-1204-z

67. Salvá B, Zumalacárregui J, Figueira AC, Osório MT, Mateo J. Nutrient composition and technological quality of meat from alpacas reared in Peru. Meat Sci 2009;82:450-5. https://doi. org/10.1016/j.meatsci.2009.02.015

68. Popova T, Tejedab L, Peñarrieta JM, Smith MA, Bush RD, Hopkins DL. Meat of South American camelids - Sensory quality and nutritional composition. Meat Sci 2021;171: 108285. https://doi.org/10.1016/j.meatsci.2020.108285

69. Pauciullo A, Shuiep ET, Ogah MD, Cosenza G, Di Stasio L, Erhardt G. Casein gene cluster in camelids: comparative genome analysis and new findings on haplotype variability and physical mapping. Front Genet 2019;10:748. https:// doi.org/10.3389/fgene.2019.00748

70. Morante R, Goyache F, Burgos A, Cervantes I, Pérez-Cabal MA, Gutiérrez JP. Genetic improvement for alpaca fibre production in the Peruvian Altiplano: the Pacomarca experience. Anim Genet Res Inf 2009;45:37-43. https://doi.org/ $10.1017 /$ S1014233909990307

71. Cruz A, Morante R, Gutiérrez JP, Torres R, Burgos A, Cervantes I. Genetic parameters for medullated fiber and its relationship with other productive traits in alpacas. Animal 2019;13:135864. https://doi.org/10.1017/S1751731118003282

72. Mendoza MN, Raudsepp T, More MJ, Gutiérrez GA, Ponce de León FA. Cytogenetic mapping of 35 new markers in the alpaca (Vicugna pacos). Genes (Basel). 2020;11:522. https:// doi.org/10.3390/genes11050522

73. Richardson MF, Munyard K, Croft LJ, et al. ChromosomeLevel alpaca reference genome VicPac3.1 Improves genomic insight into the biology of new world camelids. Front Genet 2019;10:586. https://doi.org/10.3389/fgene.2019.00586

74. Avila F, Baily MP, Perelman P, et al. A comprehensive wholegenome integrated cytogenetic map for the alpaca (Lama pacos). Cytogenet Genome Res 2014;144:193-207. https:// doi.org/10.1159/000370329
75. Jevit MJ, Davis BW, Castaneda C, et al. An $8.22 \mathrm{Mb}$ assembly and annotation of the alpaca (Vicugna pacos) Y chromosome. Genes (Basel) 2021;12:105. https://doi.org/10.3390/genes 12010105

76. Avila F, Das PJ, Kutzler M, et al. Development and application of camelid molecular cytogenetic tools. J Hered 2014;105: 952-63. https://doi.org/10.1093/jhered/ess067

77. Yue XP, Chang TC, DeJarnette JM, Marshall CE, Lei CZ, Liu WS. Copy number variation of PRAMEY across breeds and its association with male fertility in Holstein sires. J Dairy Sci 2013;96:8024-34. https://doi.org/10.3168/jds.2013-7037

78. Yue XP, Dechow C, Chang TC, et al. Copy number variations of the extensively amplified Y-linked genes, HSFY and ZNF 280BY, in cattle and their association with male reproductive traits in Holstein bulls. BMC Genomics 2014;15:113. https:// doi.org/10.1186/1471-2164-15-113

79. Pacheco HA, Rezende FM, Peñagaricano F. Gene mapping and genomic prediction of bull fertility using sex chromosome markers. J Dairy Sci 2020;103:3304-11. https://doi.org/10. 3168/jds.2019-17767

80. Vogel T, Dechend F, Manz E, et al. Organization and expression of bovine TSPY. Mamm Genome 1997;8:491. https://doi.org/ 10.1007/s003359900482

81. Wang M, Sun Z, Ding F, et al. Efficient TALEN-mediated gene knockin at the bovine $\mathrm{Y}$ chromosome and generation of a sex-reversal bovine. Cell Mol Life Sci 2021;78:5415-25. https://doi.org/10.1007/s00018-021-03855-1

82. Xi J, Wang X, Zhang Y, et al. Sex control by Zfy siRNA in the dairy cattle. Anim Reprod Sci 2019;200:1-6. https://doi. org/10.1016/j.anireprosci.2018.05.015

83. Suriaty R, Mohd Hafiz AR, Halimaton Sảadiah T, Mohd Hafizal A. Detection of y chromosome of bovine Using testis specific protein and Amelogenin genes. Malaysian J Vet Res 2016;7:47-51.

84. Sánchez JM, Gómez-Redondo I, Browne JA, Planells B, Gutiérrez-Adán A, Lonergan P. MicroRNAs in amniotic fluid and maternal blood plasma associated with sex determination and early gonad differentiation in cattle. Biol Reprod 2021;105:345-58. https://doi.org/10.1093/biolre/ioab079

85. Rhoads A, Au KF. PacBio sequencing and its applications. Genomics Proteomics Bioinformatics 2015;13:278-89. https:// doi.org/10.1016/j.gpb.2015.08.002

86. Pauciullo A, Fleck K, Lühken G, Di Berardino D, Erhardt G. Dual-color high-resolution fiber-FISH analysis on lethal white syndrome carriers in sheep. Cytogenet Genome Res 2013;140:46-54. https://doi.org/10.1159/000350786

87. Ye CJ, Heng HH. High resolution fiber-fluorescence in situ hybridization. In: Wan T, editor. Cancer cytogenetics. Methods in molecular biology. New York, NY, USA: Humana Press; 2017. v.1541. pp. 151-66. https://doi.org/10.1007/978-1-49396703-2_14

88. Lindgren G. Genome mapping in the horse [Dissertation]. 
Uppsala, Sweden: Acta Universitatis Upsaliensis; 2001.

89. Wade CM, Giulotto E, Sigurdsson S, et al. Genome sequence, comparative analysis, and population genetics of the domestic horse. Science 2009;326:865-7. https://doi.org/10.1126/science. 1178158

90. Tomaszkiewicz M, Medvedev P, Makova KD. Y and W Chromosome assemblies: approaches and discoveries. Trends Genet 2017;33:266-82. https://doi.org/10.1016/j.tig.2017. 01.008

91. Chen N, Bellott DW, Page DC, Clark AG. Identification of avian $\mathrm{W}$-linked contigs by short-read sequencing. BMC Genomics 2012;13:183. https://doi.org/10.1186/1471-216413-183

92. Galtier N. Recombination, GC-content and the human pseudoautosomal boundary paradox. Trends Genet 2004;20: 347-9. https://doi.org/10.1016/j.tig.2004.06.001

93. Katsura Y, Iwase M, Satta Y. Evolution of genomic structures on mammalian sex chromosomes. Curr Genomics 2012;13: 115-23. https://doi.org/10.2174/138920212799860625

94. Kutch IC, Fedorka KM. Y-chromosomes can constrain adaptive evolution via epistatic interactions with other chromosomes. BMC Evol Biol 2018;18:204. https://doi.org/10.1186/s12862018-1327-6

95. Bellott DW, Hughes JF, Skaletsky H, et al. Mammalian Y chromosomes retain widely expressed dosage-sensitive regulators. Nature 2014;508:494-9. https://doi.org/10.1038/ nature 13206

96. Jiang PP, Hartl DL, Lemos B. Y not a dead end: epistatic interactions between Y-linked regulatory polymorphisms and genetic background affect global gene expression in Drosophila melanogaster. Genetics 2010;186:109-18. https:// doi.org/10.1534/genetics.110.118109

97 Lemos B, Araripe LO, Hartl DL. Polymorphic Y chromosomes harbor cryptic variation with manifold functional consequences. Science 2008;319:91-3. https://doi.org/10.1126/ science. 1148861

98. Ohno S. Sex chromosomes and sex-linked genes. Berlin, Heidelberg, Germany: NY, USA: Springer-Verlag; 1967.

99. Schenkel MA, Beukeboom LW, Pen I. Epistatic interactions between sex chromosomes and autosomes can affect the stability of sex determination systems. J Evol Biol 2021;34: 1666-77. https://doi.org/10.1111/jeb.13939

100. Yang H, Fries R, Stranzinger G. The sex-determining region $\mathrm{Y}(\mathrm{SRY})$ gene is mapped to $\mathrm{p} 12-\mathrm{p} 13$ of the Y chromosome in pig (Sus scrofa domestica) by in situ hybridization. Anim Genet 1993;24:297-300. https://doi.org/10.1111/j.1365-2052. 1993.tb00315.x 